\title{
Multi-scale decomposition of energy-related industrial carbon emission by an extended logarithmic mean Divisia index: a case study of Jiangxi, China
}

\author{
Junsong Jia • Huiyong Jian • Dongming Xie • \\ Zhongyu Gu $\cdot$ Chundi Chen
}

Received: 3 December 2016 / Accepted: 25 April 2018/Published online: 12 August 2019

(C) The Author(s) 2019

\begin{abstract}
Our objective has been to decompose the energy-related industrial carbon emissions (ERICE) from both the macroeconomic and the microeconomic scales using an extended logarithmic mean Divisia index (LMDI), which few scientists have applied, for
\end{abstract}

\section{J. Jia $\cdot$ Z. Gu}

Key Laboratory of Poyang Lake Wetland and Watershed Research, Ministry of Education, Jiangxi Normal University, Nanchang 330022 Jiangxi, China

\section{Z. Gu}

e-mail: guzhongyu@jxnu.edu.cn

J. Jia $(\bowtie) \cdot$ H. Jian $\cdot$ Z. Gu

School of Geography and Environment, Jiangxi Normal

University, Nanchang 330022 Jiangxi, China

e-mail: jiaaniu@126.com

\section{H. Jian}

e-mail: jhygoodjob@jxnu.edu.cn

\section{H. Jian}

Graduate School of Jiangxi Normal University, Nanchang 330022 Jiangxi, China

\section{Xie}

Jiangxi Science \& Technology Normal University,

Nanchang 330013 Jiangxi, China

e-mail: jxstnu_xdm@jxstnu.edu.cn

C. Chen $(\bowtie)$

Key Laboratory of Reservoir Aquatic Environment, Chongqing Institute of Green and Intelligent Technology, Chinese Academy of Sciences, Chongqing 400714, China

e-mail: chundichen@tongji.edu.cn
Jiangxi, China, over the period of 1998-2015. The macroeconomic factors were output, industrial structure, energy intensity, and energy structure. The microeconomic factors were investment intensity, R\&D intensity, and $R \& D$ efficiency. It was found that output, $R \& D$ intensity, and investment intensity were mainly responsible for the increase of the ERICE, and their average annual contribution rates were $33.212 \%, 9.537 \%$, and $4.200 \%$, respectively. However, considering the infeasibility of decelerating industrial activities related to these three drivers, the development pattern of a circular economy was promoted. Then, the driving effect of the energy structure was the weakest $(0.017 \%)$. Nevertheless, the potential of energy structure optimization to improve energy efficiency in Jiangxi should be given sufficient attention, e.g., greatly reducing the use of coal. Inversely, the R\&D efficiency, energy intensity, and industrial structure presented obvious mitigating effects on the ERICE $(-13.737 \%,-11$, $652 \%$, and $-7.804 \%$, respectively). Therefore, some regulatory policy instruments have been recommended. For example, carbon reduction liability and carbon labels related to $R \& D$ investment should be implemented to encourage industrial firms to improve their energy efficiency. Then, reducing the energy intensity unceasingly while inhibiting the possible rebound effect should serve as a long-term strategy for the local government. Last, the potential mitigation effect of industrial structure optimization should be given sufficient attention when designing related reduction policies. Particularly, the top five energy-intensive subsectors S33 (Production and 
Supply of Electric Power and Heat Power), S23 (Smelting and Pressing of Ferrous Metals), S17 (Processing of Petroleum, Coking, and Processing of Nuclear Fuel), S22 (Manufacture of Nonmetallic Mineral Products), and S1 (Mining and Washing of Coal) should be given priority.

Keywords Energy-related industrial carbon emissions (ERICE) - Energy efficiency · Logarithmic mean Divisia index (LMDI) - Multi-scales · Drivers · Macroeconomic · Microeconomic · Jiangxi Province

\section{Introduction}

According to the Intergovernmental Panel on Climate Change (IPCC), most of the global average surface temperature rise since the 1950 s may be caused by human activities (IPCC 2013; Qu et al. 2016). The reason is that human activities can create a large amount of greenhouse gases (GHGs) through the burning of fossil fuels such as coal, oil, and natural gas (IPCC 2006; Specht et al. 2016). Therefore, reducing the emissions of GHGs has become a common challenge in the world. As the world's largest emitter of GHGs, China has to positively confront this problem. For example, it was forecast that China's GHG emissions would reach a startling value of 11.4 billion metric tons in 2030 without any emission reduction constraints (Xiao et al. 2014). Moreover, it was reported that approximately $83 \%$ of the total GHGs had arisen from the industrial department of China (Zhang and Liu 2014). In addition, since 2000 , approximately $70 \%$ of China's energy consumption also came from the industrial sector (Liu et al. 2016). Thus, it could be concluded that the contribution of the industrial sector to the entire quantity of GHGs was extremely high in China and that we should pay sufficient attention to it. Similarly, as a central province of China, Jiangxi's industrial department has almost the same importance. In other words, as is the case for all of China, controlling and reducing energy use and the related GHG emissions of Jiangxi's industrial sector have also become a serious and urgent challenge. However, what should we do to confront this challenge? The first and most important thing could be to identify the main influencing factors (drivers) of the energy-related industrial carbon emissions (ERICE) in Jiangxi. So, Jiangxi's ERICE value was first calculated, and the factor decomposition method was adopted to analyze the ERICE drivers. Then, based on these driver-related results, some specific countermeasures or strategies could be proposed to reduce the ERICE and improve the utilization efficiency of local energy consumption. Some scholars have even explored Jiangxi's $\mathrm{CO}_{2}$ emissions from the perspectives of the power grid (Cao et al. 2016), tourism transportation (Jia et al. 2014), and developmental strategies (Zhang et al. 2012), etc., but specific investigations of the ERICE and its drivers in this region have been few. Therefore, to a certain extent, it has been innovative for us to complete this work.

For the ERICE driver analysis, there are two commonly used methods (Xiao et al. 2016; Nie et al. 2016): structural decomposition analysis (SDA) and index decomposition analysis (IDA). SDA often requires the economic data of the input-output table, while IDA only needs the aggregate data of each industrial category (Cellura et al. 2012; Cansino et al. 2016; Yang et al. 2016). In addition, SDA can only analyze the change between the limited years, while IDA usually can analyze the change between any years (Hoekstra and van der Bergh 2003; Moutinho et al. 2016). Therefore, considering the available data of the industrial sector in Jiangxi, the IDA method was adopted for this investigation. In the IDA methods, there are still many optional indices for quantifying the impacts of factorial changes on the aggregating industrial sector. These indices are, for instance, the Laspeyres index (Lu et al. 2014), the Paasche index (Liu et al. 2016), the Arithmetic Mean Divisia index (Hatzigeorgiou et al. 2008), and the Logarithmic Mean Divisia Index (LMDI) (Ang 2005; Wang et al. 2005; Lee and Oh 2006; Wood and Lenzen 2006). Among them, the LMDI has become the most popular one because of its incomparable advantages (Chen 2011; Tan et al. 2011; Ren et al. 2012; Zhang et al. 2013; Tian et al. 2013; Shao et al. 2016). For example, it was concluded that the LMDI had some outstanding properties in its theoretical foundation (i.e., no unexplained residuals), adaptability, ease of use, and result interpretation (Ang and Liu 2001; Ang et al. 2003; Ang 2004, 2005; Ang and Liu 2007). Therefore, the LMDI model was chosen to study the ERICE drivers of Jiangxi. This model already was adopted to analyze the carbon emissions or energy consumptions or other environmental changes of some special places. For example, it has been used to analyze the change of industrial $\mathrm{CO}_{2}$ emissions (Liu et al. 2007; Marcucci and Fragkos 2015; Guo et al. 2016), energy intensity (Ma and Stern 2008; Kerimray et al. 2018), and the food consumption 
CE values of all of China (Lin and Xie 2016). Similarly, it has also been used to research the same issues at other different scales (global, national or urban), i.e., the European Union (Moutinho et al. 2015; Kopidou et al. 2016), South Korea (Jung et al. 2012), Shanghai (Zhao et al. 2010), Jiangsu (Wang et al. 2013), Taiwan (Lin et al. 2006), Yunnan (Deng et al. 2016), Guangdong (Wang et al. 2011), and the Hotan Prefecture in Xinjiang of China (Xiong et al. 2016).

Generally, in these existing studies, the total effect on carbon emission change could be decomposed into the effects of several conventional factors such as the economic amount (output), industrial structure, energy intensity, energy mix, population, and emission coefficient. However, these effects can only address the macroeconomic influences on $\mathrm{CO}_{2}$ emissions, but cannot reveal the microeconomic roots of $\mathrm{CO}_{2}$ emission changes. For example, an enterprises' investment and R\&D decision-making have some crucial microeconomic impacts on the energy saving and emission reduction performance (Collard et al. 2005; Ang 2009; Shao et al. 2011). However, studies of these impacts have been few (or even none) in the existing literature. In fact, the ERICE changes are often determined by various drivers and it is difficult to determine real reasons from one single scale. Therefore, it is necessary to combine these microeconomic factors with conventionally macroeconomic factors to more fully and accurately study the divers of the ERICE in Jiangxi. In other words, these drivers should be investigated simultaneously at both the macroeconomic and the microeconomic levels. Thus, in this investigation, we decomposed the ERICE changes of Jiangxi not only into the conventional factors but also into some novel factors at the microeconomic level. This resulting approach could be considered to be an extension of the existing LMDI.

In addition, based on the rebound effect theory, some parts of the anticipated energy savings and emission reductions from the improvement of energy efficiency may be offset by the additional energy consumption and corresponding carbon emissions resulting from the new round of economic growth induced by technological progress (Sorrell and Binswanger 2001; Sorrell and Dimitropoulos 2008; Sorrell et al. 2009; Shao et al. 2011, 2014, 2016). So, if the equipment updates and R\&D efforts of industrial enterprises are targeting energy savings and emission reductions, the related investment and R\&D activities will facilitate the reduction of the ERICE. However, if they are targeting the expansion of the production and productivity improvements, the investment and R\&D activities may induce an additional increase in the energy consumption and carbon emissions. In other words, the complexity of the problem clearly increases with the introduction of the relative investment and R\&D factors into the LMDI model. The corresponding results and conclusions, however, may be of more significance. Thus, this idea was also adopted in this investigation.

It should be noted that, starting in 1953, with a gap during 1963-1965, the government of China has proposed plans for national economic and social development every 5 years, namely, the "Five-Year Plan". For example, in the 12th "Five-Year Plan" (2011-2015), China announced that it would try hard to reduce carbon emissions through a variety of measures and that the carbon emission intensity in 2015 should be reduced by $17 \%$ compared with the 2010 level (SCPRC 2011). As a result of the 5year planning cycle, China's development also presented an obvious 5-year periodic property. Correspondingly, as a province of China, similar plans have also been implemented every 5 years, such as the 9th, 10th, 11th, and 12th "Five-Year Plan" periods in Jiangxi, which were consistent with the periods of 1996-2000, 2001-2005, 2006-2010, and 2011-2015, respectively. In these plans, the items of energy conservation and improving energy use efficiency were all mentioned, required, and planned at varying degrees. Particularly, during the 12th "Five-Year Plan" of Jiangxi, the comprehensive energy consumption per GDP was planned to decrease by $16 \%$, which was based on the result that it had decreased by $20 \%$ during the 11 th "Five-Year Plan". Therefore, overall, the energy consumption intensity of Jiangxi had a decreasing trend over the studied period of 1998-2015. However, the severe acute respiratory syndrome (SARS) crisis and global financial crisis began in 2003 and 2008, respectively, which might cause some interference in the implementation of the government's energy conservation policies and measures. Thus, the factors of plans and emergencies were also researched in this investigation. The remaining parts of this paper are organized as follows. The method of ERICE calculation, the extended LMDI decomposition model, and the corresponding data sources are presented in section "Methodology and data". The results of the ERICE, the decomposition result analysis, and 
related discussions are presented in section "Results and discussion". Some conclusions are summarized and some particular countermeasures for the sustainable future or low carbon development of Jiangxi, especially in the industrial sector, are proposed in section "Conclusions".

\section{Methodology and data}

\section{ERICE calculation}

The total ERICE (abbreviated as $\mathrm{C}$ in the following equations) was calculated based on the energy consumption data, carbon emission coefficient, and the fuel's oxidation percentage, as recommended by the IPCC (2006):

$C=\sum_{i=1}^{35} C_{i}=\sum_{i=1}^{35} \sum_{j=1}^{9} C_{i j}=\sum_{i=1}^{35} \sum_{j=1}^{9} E_{i j} \cdot f_{j}$

where the meanings of the corresponding variables are listed in Table 1 . For example, $E_{i j}$ denotes the consumption amount of fuel $\mathrm{j}$ in industry $\mathrm{i}$, its units are metric tons of standard coal equivalent (tce).

The extended LMDI model

The total ERICE changes were decomposed not only into the conventional factors at the macroeconomic level but also into some novel factors at the microeconomic level. Therefore, the extended LMDI model contained the following eight factors:

$$
\begin{gathered}
C=\sum_{i=1}^{35} \sum_{j=1}^{9} C_{i j}=\sum_{i=1}^{35} \sum_{j=1}^{9} \frac{C_{i j}}{E_{i j}} \cdot \frac{E_{i j}}{E_{i}} \cdot \frac{E_{i}}{O_{i}} \cdot \frac{O_{i}}{R_{i}} \cdot \frac{R_{i}}{I_{i}} \cdot \frac{I_{i}}{O_{i}} \cdot \frac{O_{i}}{O} \cdot O \\
=\sum_{i=1}^{35} \sum_{j=1}^{9} f_{j} \cdot E S_{i} \cdot E I_{i} \cdot R E_{i} \cdot R I_{i} \cdot I I_{i} \cdot I S_{i} \cdot O
\end{gathered}
$$

where the meanings of these variables are also listed in Table 1.

Taking the logarithmic differentiation of equation (2) based on time, we obtain

$\frac{d \ln C}{d t}=\sum_{i=1}^{35} \sum_{j=1}^{9}\left[\varphi_{i j}(t) \cdot\left(\frac{d \ln f_{j}}{d t}+\frac{d \ln E S_{i}}{d t}+\frac{d \ln E I_{i}}{d t}+\frac{d \ln R E_{i}}{d t}+\frac{d \ln R I_{i}}{d t}+\frac{d \ln I I_{i}}{d t}+\frac{d \ln I S_{i}}{d t}+\frac{d \ln O}{d t}\right)\right]$

where $\varphi_{i j}(t)=\frac{f_{j} \cdot E S_{i} \cdot E I_{i} \cdot R E_{i} \cdot R I_{i} \cdot I I_{i} \cdot I S_{i} \cdot O}{C}=\frac{C_{i j}}{C}$.

Integrating equation (3) over the time interval [0, T], we obtain

$\ln \frac{C_{T}}{C_{0}}=\sum_{i=1}^{35} \sum_{j=1}^{9} \int_{0}^{T} \varphi_{i j}(t) \cdot\left(\frac{d \ln f_{j}}{d t}+\frac{d \ln E S_{i}}{d t}+\frac{d \ln E I_{i}}{d t}+\frac{d \ln R E_{i}}{d t}+\frac{d \ln R I_{i}}{d t}+\frac{d \ln I I_{i}}{d t}+\frac{d \ln I S_{i}}{d t}+\frac{d \ln O}{d t}\right) \cdot d t$

Then, we obtain the exponentiation of equation (4):

$$
\begin{aligned}
& \frac{C_{T}}{C_{0}}=\exp \left(\sum_{i=1}^{35} \sum_{j=1}^{9} \int_{0}^{T} \varphi_{i j}(t) \frac{d \ln f_{j}}{d t} d t\right) \cdot \exp \left(\sum_{i=1}^{35} \sum_{j=1}^{9} \int_{0}^{T} \varphi_{i j}(t) \frac{d \ln E S_{i}}{d t} d t\right) \cdot \exp \left(\sum_{i=1}^{35} \sum_{j=1}^{9} \int_{0}^{T} \varphi_{i j}(t) \frac{d \ln E I_{i}}{d t} d t\right) \\
& \cdot \exp \left(\sum_{i=1}^{35} \sum_{j=1}^{9} \int_{0}^{T} \varphi_{i j}(t) \frac{d \ln R E_{i}}{d t} d t\right) \cdot \exp \left(\sum_{i=1}^{35} \sum_{j=1}^{9} \int_{0}^{T} \varphi_{i j}(t) \frac{d \ln R I_{i}}{d t} d t\right) \cdot \exp \left(\sum_{i=1}^{35} \sum_{j=1}^{9} \int_{0}^{T} \varphi_{i j}(t) \frac{d \ln I I_{i}}{d t} d t\right) \\
& \cdot \exp \left(\sum_{i=1}^{35} \sum_{j=1}^{9} \int_{0}^{T} \varphi_{i j}(t) \frac{d \ln I S_{i}}{d t} d t\right) \cdot \exp \left(\sum_{i=1}^{35} \sum_{j=1}^{9} \int_{0}^{T} \varphi_{i j}(t) \frac{d \ln O}{d t} d t\right)
\end{aligned}
$$


Table 1 Meanings of the major variables

\begin{tabular}{|c|c|c|}
\hline Variables & Meaning & Unit \\
\hline $\mathrm{i}$ & Industrial subsectors, $\mathrm{i}=1,2, \ldots, 35$ & \\
\hline $\mathrm{j}$ & Fuel's categories, $\mathrm{j}=1,2, \ldots, 9$ & \\
\hline$C_{i}$ & $\mathrm{CO}_{2}$ emission of industry $\mathrm{i}$ & Mt \\
\hline$C_{i j}$ & $\mathrm{CO}_{2}$ emission of industry $\mathrm{i}$ by using fuel $\mathrm{j}$ & Mt \\
\hline$E_{i j}$ & Consumption amount of fuel $\mathrm{j}$ in industry $\mathrm{i}$ & tce \\
\hline$f_{j}$ & $\mathrm{CO}_{2}$ emission's coefficient of fuel $\mathrm{j}$ & $\mathrm{t} / \mathrm{tce}$ \\
\hline$E_{i}$ & Total energy consumption amount of subsector i & tce \\
\hline$O_{i}$ & Industrial output of subsector i & RMB \\
\hline$R_{i}$ & $R \& D$ expenditure of subsector $i$ & RMB \\
\hline$I_{i}$ & Fixed asset investment of subsector i & $\mathrm{RMB}$ \\
\hline $\mathrm{O}$ & Total industrial output & $\mathrm{RMB}$ \\
\hline$E S_{i}$ & Energy structure: shares of different fuels in gross energy consumption of subsector i & $\%$ \\
\hline$E I_{i}$ & Energy intensity: energy consumption per unit output in subsector i & tce/RMB \\
\hline$R E_{i}$ & R\&D efficiency: output per unit of R\&D expenditure in subsector i & \\
\hline$R I_{i}$ & R\&D intensity: share of R\&D expenditure in fixed asset investment of subsector $i$ & $\%$ \\
\hline$I I_{i}$ & Investment intensity: share of fixed asset investment in output of subsector i & $\%$ \\
\hline$I S_{i}$ & Industrial structure: output share of subsector $\mathrm{i}$ in total industrial output & $\%$ \\
\hline
\end{tabular}

Note: "null" denotes that the corresponding indicator has only an absolute number and no units. Mt and RMB are the acronyms for "million metric tons" and "Chinese Yuan", respectively. In $f_{j}$, the fuel's oxidation percentages were selected according to the literature (Shao et al. 2016) and are listed in Appendix Table 5

In accordance with the definite integral middle value theorem, equation (5) can be transformed as

$$
\begin{aligned}
& \frac{C_{T}}{C_{0}} \cong \exp \left(\sum_{i=1}^{35} \sum_{j=1}^{9} \varphi_{i j}\left(t^{*}\right) \ln \frac{f_{j, T}}{f_{j, 0}}\right) \cdot \exp \left(\sum_{i=1}^{35} \sum_{j=1}^{9} \varphi_{i j}\left(t^{*}\right) \ln \frac{E S_{i, T}}{E S_{i, 0}}\right) \cdot \exp \left(\sum_{i=1}^{35} \sum_{j=1}^{9} \varphi_{i j}\left(t^{*}\right) \ln \frac{E I_{i, T}}{E I_{i, 0}}\right) \\
& \cdot \exp \left(\sum_{i=1}^{35} \sum_{j=1}^{9} \varphi_{i j}\left(t^{*}\right) \ln \frac{R E_{i, T}}{R E_{i, 0}}\right) \cdot \exp \left(\sum_{i=1}^{35} \sum_{j=1}^{9} \varphi_{i j}\left(t^{*}\right) \ln \frac{R I_{i, T}}{R I_{i, 0}}\right) \cdot \exp \left(\sum_{i=1}^{35} \sum_{j=1}^{9} \varphi_{i j}\left(t^{*}\right) \ln \frac{I I_{i, T}}{I I_{i, 0}}\right) \\
& \cdot \exp \left(\sum_{i=1}^{35} \sum_{j=1}^{9} \varphi_{i j}\left(t^{*}\right) \ln \frac{I S_{i, T}}{I S_{i, 0}}\right) \cdot \exp \left(\sum_{i=1}^{35} \sum_{j=1}^{9} \varphi_{i j}\left(t^{*}\right) \ln \frac{O_{T}}{O_{0}}\right)
\end{aligned}
$$

where $\varphi_{i j}(t *)$ is the weight function given by $\varphi_{i j}(t)=\frac{C_{i j}}{C}$ above at point $t * \in[0, T]$.

According to the logarithmic mean weight function recommended by Ang and Liu (2001), the weight function of $\varphi_{i j}(t *)$ can be expressed as

$\varphi_{i j}\left(t^{*}\right)=\frac{L\left(C_{i j, T}, C_{i j, 0}\right)}{L\left(C_{T}, C_{0}\right)}$

where the logarithmic mean of two positive numbers is

$$
L(x, y)=\left\{\begin{array}{cc}
(x-y) /(\ln x-\ln y), & x \neq y>0 \\
x & x=y>0
\end{array} .\right.
$$

Then, the equation (6) can be simplified as

$$
\Psi C_{T O T}=C_{T} / C_{0}=\Psi C_{f} \cdot \Psi C_{E S} \cdot \Psi C_{E I} \cdot \Psi C_{R E} \cdot \Psi C_{R I} \cdot \Psi C_{I I} \cdot \Psi C_{I S} \cdot \Psi C_{O}
$$


where

$\Psi C_{\zeta}=\exp \left(\sum_{i=1}^{35} \sum_{j=1}^{9} \frac{\left(C_{i j, T}-C_{i j, 0}\right) /\left(\ln C_{i j, T}-\ln C_{i j, 0}\right)}{\left(C_{T}-C_{0}\right) /\left(\ln C_{T}-\ln C_{0}\right)} \cdot \ln \frac{\zeta_{i j, T}}{\zeta_{i j, 0}}\right)$,

and $\zeta$ denoted f, ES, EI, RE, RI, II, IS, and O. $\Psi C_{f}, \Psi C_{E S}$, $\Psi C_{E I}, \Psi C_{R E}, \Psi C_{R I}, \Psi C_{I I}, \Psi C_{I S}$, and $\Psi C_{O}$ are, respectively, the emission's coefficient effect, the energy structure effect, the energy intensity effect, the R\&D efficiency effect, the R\&D intensity effect, the investment intensity effect, the industrial structure effect, and the output effect.

Equation (9) is the multiplicative formation of the LMDI model for the ERICE changes. The corresponding additive formation of LMDI decomposition can be written as follows based on the work of Ang (2005) and $\mathrm{Xu}$ et al. (2017):

$$
\begin{aligned}
\Delta C_{T O T}=C_{T}-C_{0}= & \Delta C_{f}+\Delta C_{E S}+\Delta C_{E I} \\
& +\Delta C_{R E}+\Delta C_{R I}+\Delta C_{I I} \\
& +\Delta C_{I S}+\Delta C_{O} .
\end{aligned}
$$

where $\Delta C_{\zeta}=\sum_{i=1}^{35} \sum_{j=1}^{9} \frac{C_{i j, T}-C_{i j, 0}}{\ln C_{i j, T}-\ln C_{i j, 0}} \cdot \ln \frac{\zeta_{i j, T}}{\zeta_{i j, 0}}$. Correspondingly, $\Delta C_{f}, \Delta C_{E S}, \Delta C_{E I}, \Delta C_{R E}, \Delta C_{R I}, \Delta C_{I I}, \Delta C_{I S}$, and $\Delta C_{O}$ are, respectively, the additive formations of the emission's coefficient effect, the energy structure effect, the energy intensity effect, the R\&D efficiency effect, the R\&D intensity effect, the investment intensity effect, the industrial structure effect, and the output effect.

It should be explained that, according to the article of Ang et al. (2003), the LMDI decomposition mentioned above is actually the pattern of LMDI I and there is another pattern of decomposition, which is regarded as the LMDI II. Considering that the decomposition results for LMDI I and LMDI II are consistent, the decomposition by LMDI II was omitted for saving space. Moreover, the $\mathrm{CO}_{2}$ emission coefficients of the various fuels were all assumed to be fixed when calculating Jiangxi's ERICE. Therefore, they, in reality, had no contributions to the ERICE changes. In other words, here, the $\Psi C_{f}$ and $\Delta C_{f}$ in equations (9) and (10) should be 1 and 0 , respectively. Hence, the final drivers of Jiangxi's ERICE changes were decomposed into seven corresponding indicators. In addition, among the seven indicators, ES, EI, IS, and O are four conventional macroeconomic factors, and RE, RI, and II are three potential microeconomic drivers of which few have been previously studied by scholars, especially in Jiangxi. Therefore, they have been given much more attention in the following text. Particularly, RE means the R\&D efficiency, reflecting the transformation capacity of R\&D expenditure on output. In the condition of all other factors being unchanged, the greater the value of RE, the more the output transformed from R\&D expenditure is. Similarly, the RI means the R\&D intensity, reflecting the innovation impetus and technological content of the industrial subsector. The greater the value of RI, the stronger the innovation enthusiasm is. The II means the investment intensity, reflecting the intensity of expanded production in the industrial subsector. The greater the value of II, the stronger the capacity of expanded production is. Therefore, we could easily find the three novel microeconomic level factors that embodied the industrial investment and R\&D activities from the enterprise's perspective. The extended LMDI model might give us much more useful information and deserved being considered thoroughly.

\section{Data description}

The studied province (Jiangxi of China) is located at $24^{\circ} 29^{\prime} 14^{\prime \prime}-30^{\circ} 04^{\prime} 41^{\prime \prime} \mathrm{N}$ and $113^{\circ} 34^{\prime} 36^{\prime \prime}-118^{\circ}$ $28^{\prime} 58^{\prime \prime}$ E, with an administrative area of $166,900 \mathrm{~km}^{2}$. So, all the related economic and energy data were derived from the Jiangxi Statistical Yearbook (1999-2016). As the leading principle in the IPCC method (2006), the use of the special parameters of each country is encouraged to assure the accuracy of the results. So, as used in the article of Shao et al. (2016), some related parameters announced officially in China were also adopted in this investigation. To eliminate the influence of price changes, we deflated the raw data at the current prices to constant 2010 prices using the corresponding price indices. To obtain more accurate results, we considered all nine fossil fuels reported in the statistical yearbooks. They were raw coal, cleaned coal, other cleaned coal, coke, crude oil, gasoline, kerosene, diesel, and fuel oil.

The amount and share of weapons and ammunition manufacturing (WAM) in Jiangxi were marginal, and its fossil fuel consumption was close to zero in most years; so, the WAM industry was excluded. Similarly, some other industries were 
also excluded. All in all, 35 industrial subsectors were evaluated in this investigation (Table 2). The calculated ERICE values of all the subsectors during 1998-2015 are shown in Appendix Table 6.

The data of all types of energy consumption in different industrial subsectors was obtained directly from the statistical yearbook according to the government's official website (http://www.jxstj.gov.cn/Column. shtml?p5=423). Moreover, for the industrial enterprises above a designated size, the $R \& D$ expenditure reached approximately $0.7 \%$ of the total revenue of the principal businesses in 2015, according to the R\&D expenditure-related report published by the local government (http://www.jiangxi.gov. cn/zzc/ajg/sbgt/201705/t20170510_1334887.htm). Therefore, the R\&D expenditures of different industrial subsectors in 2015 were obtained by multiplying this coefficient $(0.7 \%)$ with the corresponding total revenue of principal businesses, which was also obtained directly from the statistical data. In addition, the R\&D expenditures of different industrial subsectors in other years were also calculated based on these coefficients and corresponding statistical data. Considering that the government had paid increasing emphasis on innovation and R\&D activities during 1998-2015, these coefficients were supposed to increase by $0.02 \%$ yearly from 1998 to 2015 .

\section{Results and discussion}

Overall trends of the ERICE and the contributions of various drivers

As shown in Fig. 1a, in 1998, the industrial output of Jiangxi was $69.12 \times 10^{9}$ RMB based on the constant 2010 prices, and the corresponding ERICE was 52.78 Mt (Appendix Table 6). With rapid economic growth and the improvement of people's living standards, Jiangxi's industrial output had steadily increased to $771.31 \times 10^{9} \mathrm{RMB}$ in 2015 . The growth amount was $702.19 \times 10^{9} \mathrm{RMB}$ with an average annual increase of $15.25 \%$. The corresponding ERICE also had an obvious growth to $176.37 \mathrm{Mt}$ in 2015, a growth amount of $123.59 \mathrm{Mt}$, and an average annual increase of $7.35 \%$ (Fig. 1a).

Table 2 Classification of industrial subsectors

\begin{tabular}{|c|c|c|c|}
\hline No. & Sector & No. & Sector \\
\hline S1 & Mining and Washing of Coal & S19 & Manufacture of Medicines \\
\hline S2 & Mining and Processing of Ferrous Metal Ores & $\mathrm{S} 20$ & Manufacture of Chemical Fibers \\
\hline S3 & Mining and Processing of Non-Ferrous Metal Ores & $\mathrm{S} 21$ & Manufacture of Rubber \& Plastics \\
\hline S4 & Mining and Processing of Nonmetal Ores & $\mathrm{S} 22$ & Manufacture of Non-metallic Mineral Products \\
\hline S5 & Processing of Food from Agricultural Products & $\mathrm{S} 23$ & Smelting and Pressing of Ferrous Metals \\
\hline S6 & Manufacture of Foods & $\mathrm{S} 24$ & Smelting and Pressing of Non-ferrous Metals \\
\hline S7 & Manufacture of Beverages & $\mathrm{S} 25$ & Manufacture of Metal Products \\
\hline S8 & Manufacture of Tobacco & $\mathrm{S} 26$ & Manufacture of General Purpose Machinery \\
\hline S9 & Manufacture of Textile & $\mathrm{S} 27$ & Manufacture of Special Purpose Machinery \\
\hline $\mathrm{S} 10$ & Manufacture of Textile Wearing Apparel, Footware and Caps & $\mathrm{S} 28$ & Manufacture of Transport Equipment \\
\hline S11 & Manufacture of Leather, Fur, Feather and Related Products & S29 & Manufacture of Electrical Machinery and Equipment \\
\hline S12 & $\begin{array}{l}\text { Processing of Timber, Manufacture of Wood, Bamboo, } \\
\text { Rattan, Palm, and Straw Products }\end{array}$ & $\mathrm{S} 30$ & $\begin{array}{l}\text { Manufacture of Communication Equipment, Computers and } \\
\text { Other Electronic Equipment }\end{array}$ \\
\hline S13 & Manufacture of Furniture & $\mathrm{S} 31$ & $\begin{array}{l}\text { Manufacture of Measuring Instruments and Machinery for } \\
\text { Cultural Activity and Office Work }\end{array}$ \\
\hline $\mathrm{S} 14$ & Manufacture of Paper and Paper Products & $\mathrm{S} 32$ & Manufacture of Artwork and Other Manufacturing \\
\hline $\mathrm{S} 15$ & Printing, Reproduction of Recording Media & $\mathrm{S} 33$ & Production and Supply of Electric Power and Heat Power \\
\hline $\mathrm{S} 16$ & Manufacture of Articles for Culture, Education and Sport & $\mathrm{S} 34$ & Production and Supply of Gas \\
\hline S17 & Processing of Petroleum, Coking, Processing of Nuclear Fuel & $\mathrm{S} 35$ & Production and Supply of Water \\
\hline $\mathrm{S} 18$ & $\begin{array}{l}\text { Manufacture of Raw Chemical Materials and Chemical } \\
\text { Products }\end{array}$ & & \\
\hline
\end{tabular}


$\longrightarrow$ Output —ERICE - Carbon intensity

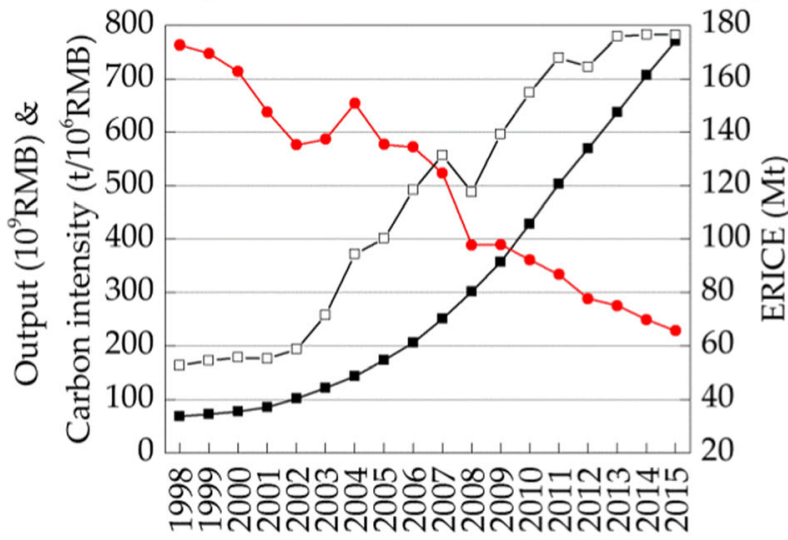

(a)

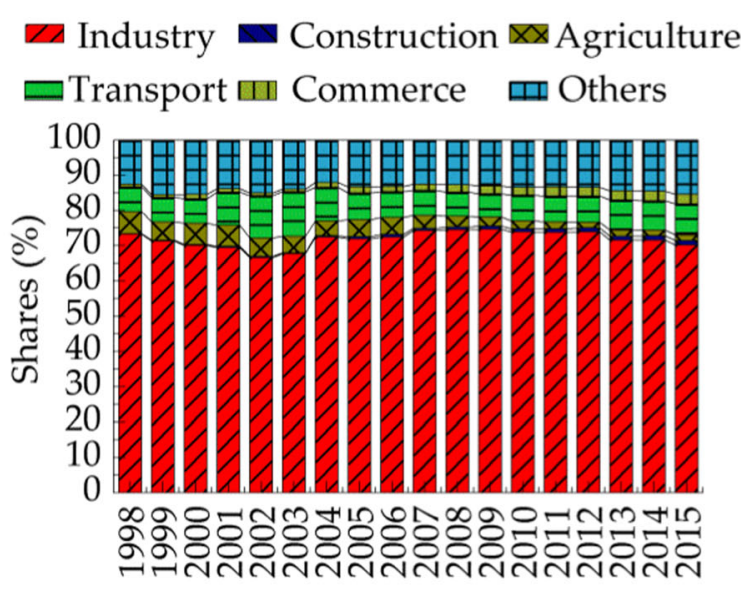

(b)

Fig. 1 The energy-related industrial carbon emissions (ERICE), industrial output, carbon intensity (a), and the structure of total energyrelated $\mathrm{CO}_{2}$ in Jiangxi (b)

Therefore, the carbon intensity of Jiangxi overall had a decrease during 1998-2015, because of the higher increasing rate of the industrial output $(15.25 \%)$ than that of the ERICE $(7.35 \%)$. There was an exceptional change of the growth rate during 2003-2004, which might have been the result of the break out of "SARS". Similarly, the stable situation in 2008-2009 might have been the result of the "financial crisis" at that time.

It is very noteworthy that the industrial sector share has always remained at $70 \%( \pm 4 \%)$ in the total energyrelated $\mathrm{CO}_{2}$ of Jiangxi from all the production sectors such as construction, agriculture, and transport (Fig. 1b). Thus, we can also conclude that the Jiangxi's energy consumption in the industrial sector and the ERICE might play a vital and decisive role in its economic growth. Particularly, the multiplicative decomposition results of Jiangxi's ERICE change in three "Five-Year Plan" periods and the entire period as are presented in Appendix Fig. 14. The corresponding additive decomposition results are shown in Fig. 2. Their detailed results are shown in Appendix Tables 7 and 8. Overall, Jiangxi's ERICE experienced an increasing trend. It increased by $123.59 \mathrm{Mt}$ from 1998 to 2015 (Fig. 2 and Appendix Table 8), with a growth rate of $234.2 \%$ (Appendix Table 7). The ERICE also presented an increasing trend during the three consecutive "Five-Year Plan" stages (Fig. 2 and Appendix Table 7).

During the 10th "Five-Year Plan" period (20002005), the ERICE growth was 44.61 Mt. However, in the 11th "Five-Year Plan" period (2005-2010), the
ERICE had a larger rise of 54.66 Mt. The reason can be attributed to the acceleration of industrialization in Jiangxi reflected by the quick rise of the proportion of industry output from $35.9 \%$ in 2005 to $45.5 \%$ in 2010. During the 12th "Five-Year Plan" period (2010-2015), Jiangxi's ERICE had a smaller rise than the previous two periods, with only a growth of $21.43 \mathrm{Mt}$ and the lowest rate of increase rate $(13.8 \%)$, which might be closely related to the industrial structural transformation. As we know, the global financial crisis began in 2008. After that, the sustainable development of the social economy received increasing attention and the transformation of the industrial structure naturally received great impetus arising from some effective emissionreduction actions of government. As a result, the proportion of tertiary industry output increased from $33.0 \%$ in 2010 to $39.1 \%$ in 2015 . Therefore, we found that these emission-reduction efforts such as industrial structure updating surely had a positive effect of mitigating the ERICE growth.

Next, the contributions of various factors to the ERICE changes are listed in Table 3. From this data, we can easily see that with contributions from high to low orders during 1998-2015, the promotion factors of the ERICE in Jiangxi were output (564.6\%), R\&D intensity (162.1\%), investment intensity $(71.4 \%)$, and energy structure $(0.3 \%)$, while the mitigating factors of the ERICE were R\&D efficiency $(-233.5 \%)$, energy intensity $(-198.1 \%)$, and industrial structure $(-132.7 \%)$. The total promotional effects $(564.6 \%+162.1 \%+71.4 \%+$ 

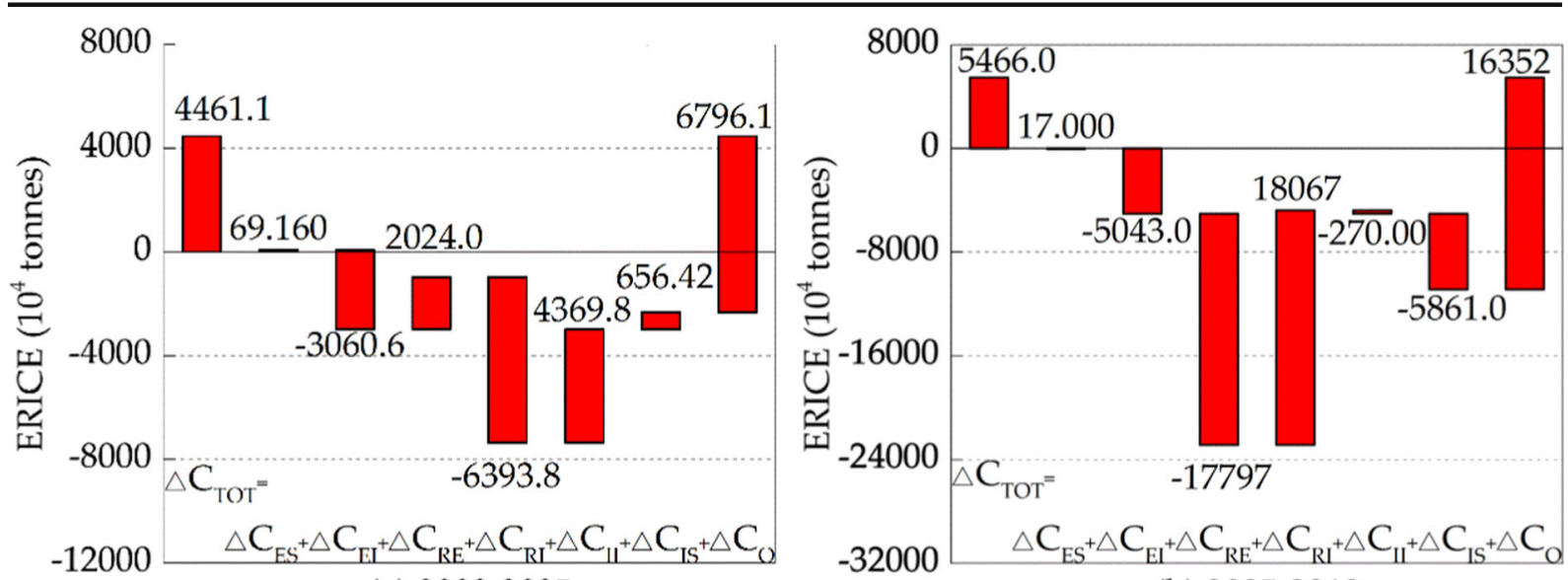

(a) 2000-2005

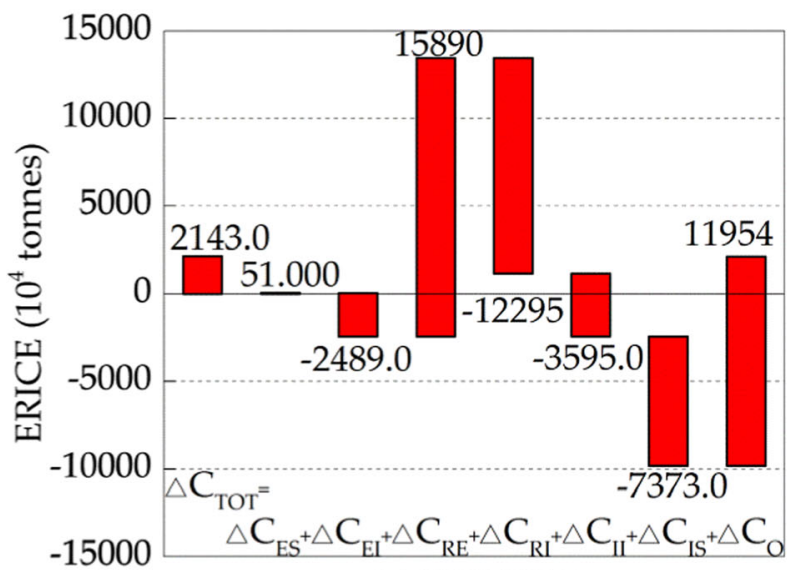

(c) 2010-2015

Fig. 2 Additive decomposition results of Jiangxi's ERICE changes in the three "Five-Year Plan" periods and the entire period $\left(\Delta \mathrm{C}_{\mathrm{ES}}, \Delta_{\mathrm{EI}}, \mathrm{C}_{\mathrm{RE}}, \Delta \mathrm{C}_{\mathrm{RI}},{ } \mathrm{C}_{\mathrm{II}},{ }^{\circ} \mathrm{C}_{\mathrm{IS}}\right.$, and $\Delta \mathrm{C}_{\mathrm{O}}$ denote the effects of energy structure, energy intensity, $R \& D$ efficiency, $R \& D$

$0.3 \%=798.4 \%)$ were much greater than the total mitigating effects $(233.5 \%+198.1 \%+132.7 \%=$ $564.3 \%$ ), which caused a remarkable increase of $234.2 \%(=798.4-564.3 \%)$ in the total ERICE over the period of 1998-2015 (Table 3). Particularly, the multiplicative and additive decomposition results of the output were 18.34 and 298.03 Mt (Appendix Fig. 14d and Fig. 3d), respectively, indicating that the output was the largest driver of the ERICE growth (Fig. 3).

Considering that cumulative decomposition results stabilize the short-term fluctuant effects of the various factors to provide a more credible comparison (Ma and Stern 2008; Shao et al. 2016), they are listed in Appendix Table 9 and depicted in Fig. 3. Here, the term "cumulative" means the following. Let us suppose that

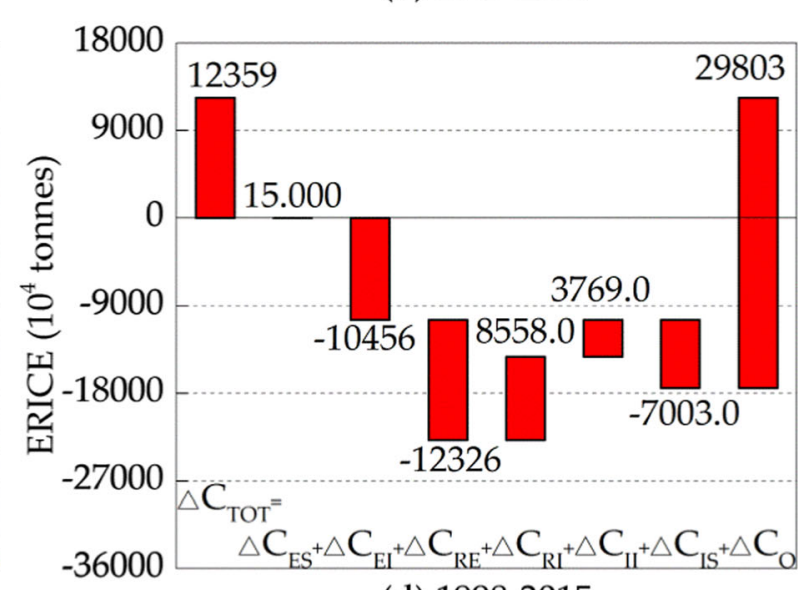

(d) $1998-2015$

intensity, investment intensity, industrial structure, and output on the ERICE changes, respectively). a 2000-2005. b 2005-2010. c 2010-2015. d 1998-2015

the decomposition results of all the ERICE change indices in 1998 were 1 . The cumulative decomposition results of 1999 are the corresponding multiplicative values of 1998-1999. Then, the cumulative decomposition results in 2000 are the multiplicative values of 1998-1999 multiplied by the multiplicative values of 1999-2000 and so on. It should be noted that we separately drew the results of RI, II, and RE in Fig. $3 b$ to clearly present them due to their high fluctuations.

Over the 1998-2015 period, among the five macroeconomic factors shown in Fig. 3a, only the output always had a positive effect on the ERICE and presented a sharp upward trend. This result is consistent with the information presented in Fig. $2 \mathrm{~d}$ and means that the output expansion is the dominant effect for ERICE growth. The other macroeconomic factors had trivial 
Table 3 Contributions of the various factors to the ERICE changes (unit: \%)

\begin{tabular}{|c|c|c|c|c|c|c|c|c|}
\hline Stage & Changes & $\begin{array}{l}\text { Energy } \\
\text { structure }\end{array}$ & $\begin{array}{l}\text { Energy } \\
\text { intensity }\end{array}$ & $\begin{array}{l}\text { R\&D } \\
\text { efficiency }\end{array}$ & $\begin{array}{l}\text { R\&D } \\
\text { intensity }\end{array}$ & $\begin{array}{l}\text { Investment } \\
\text { intensity }\end{array}$ & $\begin{array}{l}\text { Industrial } \\
\text { structure }\end{array}$ & Output \\
\hline 1998-1999 & 3.26 & -1.22 & -3.03 & 3.79 & 17.76 & -21.54 & 10.99 & -3.48 \\
\hline 1999-2000 & 2.14 & -0.23 & -4.14 & -108.78 & 95.95 & 12.83 & -1.52 & 8.03 \\
\hline 2000-2001 & -0.93 & 0.21 & 0.58 & -14.90 & -9.98 & 24.88 & 1.39 & -3.10 \\
\hline 2001-2002 & 6.69 & 0.09 & -16.37 & -84.61 & 80.77 & 3.84 & 8.55 & 14.41 \\
\hline $2002-2003$ & 21.67 & -0.02 & 3.18 & 3.48 & -37.33 & 33.86 & -5.21 & 23.72 \\
\hline 2003-2004 & 31.83 & 0.59 & -13.75 & 130.07 & -122.51 & -7.56 & 7.94 & 37.04 \\
\hline 2004-2005 & 6.25 & 0.12 & -16.90 & 8.44 & -11.13 & 2.69 & -3.52 & 26.54 \\
\hline 2005-2006 & 18.00 & 0.04 & -3.60 & -58.63 & 103.98 & -45.35 & -10.74 & 32.30 \\
\hline 2006-2007 & 11.04 & 0.28 & -7.10 & 6.78 & -34.86 & 28.08 & -15.54 & 33.40 \\
\hline 2007-2008 & 1.67 & -0.15 & -15.02 & -65.91 & 37.28 & 28.63 & -5.40 & 22.23 \\
\hline 2008-2009 & 4.39 & 0.02 & -6.88 & -37.74 & 18.40 & 19.33 & -8.77 & 20.02 \\
\hline 2009-2010 & 11.11 & -0.04 & -10.32 & 8.47 & 28.36 & -36.83 & -7.42 & 28.89 \\
\hline $2010-2011$ & 8.42 & 0.36 & -2.21 & 142.81 & -144.05 & 1.24 & -6.58 & 16.85 \\
\hline 2011-2012 & -2.00 & -0.06 & -8.87 & 6.71 & 10.42 & -17.13 & -8.16 & 15.09 \\
\hline $2012-2013$ & 6.85 & 0.07 & -1.12 & 93.48 & -102.52 & 9.05 & -8.57 & 16.47 \\
\hline 2013-2014 & 0.38 & 0.25 & -4.42 & -46.04 & 44.72 & 1.32 & -11.31 & 15.86 \\
\hline 2014-2015 & -0.11 & -0.32 & 1.79 & -91.24 & 107.40 & -16.16 & -10.52 & 8.93 \\
\hline 2000-2005 & 80.13 & 1.24 & -54.97 & 36.36 & -114.85 & 78.49 & 11.79 & 122.07 \\
\hline 2005-2010 & 54.50 & 0.17 & -50.28 & -177.46 & 180.15 & -2.69 & -58.44 & 163.05 \\
\hline $2010-2015$ & 13.83 & 0.33 & -16.06 & 102.53 & -79.33 & -23.20 & -47.57 & 77.13 \\
\hline 1998-2015 & 234.15 & 0.29 & -198.09 & -233.53 & 162.13 & 71.40 & -132.67 & 564.62 \\
\hline
\end{tabular}

Note: "-" denotes the positive (favorable) contribution of reducing the ERICE

effects on the ERICE. Among them, energy intensity had the strongest emission-mitigating effect. Industrial structure followed it. With respect to the other three

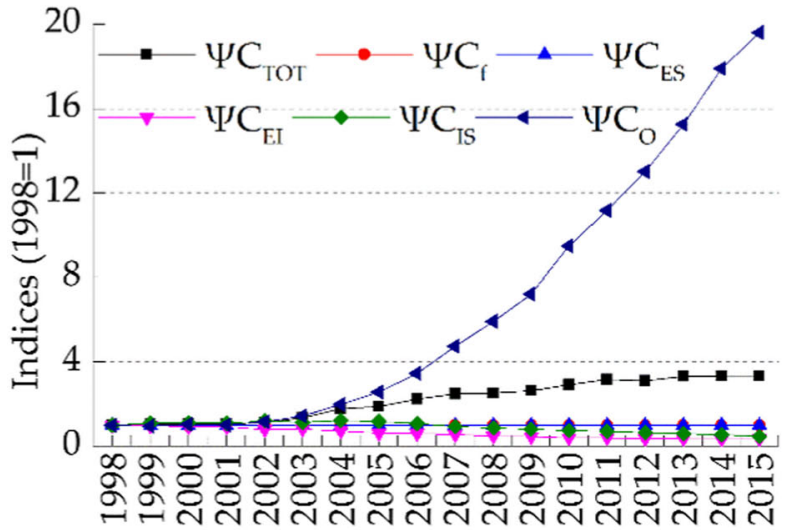

(a) Trends of five macroeconomic factors

Fig. 3 Indices' trends of the cumulative decomposition results of the ERICE changes $(1998=1)\left(\Psi \mathrm{C}_{\mathrm{TOT}}, \Psi \mathrm{C}_{\mathrm{f}}, \Psi \mathrm{C}_{\mathrm{ES}}, \Psi \mathrm{C}_{\mathrm{EI}}\right.$, $\Psi \mathrm{C}_{\mathrm{IS}}, \Psi \mathrm{C}_{\mathrm{O}}, \Psi \mathrm{C}_{\mathrm{RI}}, \Psi \mathrm{C}_{\mathrm{II}}$, and $\Psi \mathrm{C}_{\mathrm{RE}}$ denote the total changes and the effects' indices of emission coefficient, energy structure, microeconomic factors, the R\&D efficiency showed frequent fluctuations, with a circuitous downward trend (mitigating effects). Inversely, the investment intensity

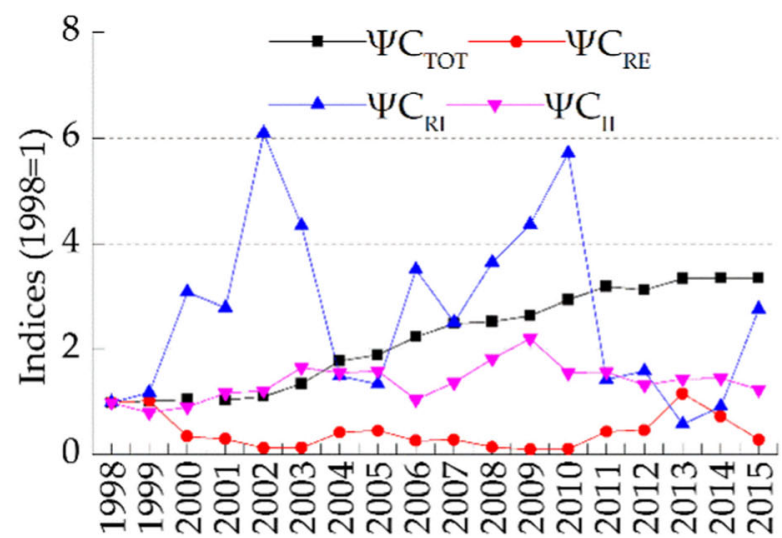

(b) Trends of three microeconomic factors

energy intensity, industrial structure, output, R\&D intensity, investment intensity, and R\&D efficiency on the ERICE changes, respectively). a Trends of the five macroeconomic factors. $\mathbf{b}$ Trends of the three microeconomic factors 
also showed frequent fluctuations, but with a circuitous upward trend (driving effects). Similarly, the R\&D intensity presented the most prominent fluctuations and had a major driving effect on the ERICE (Fig. 3b). Overall, all the three microeconomic factors exerted the most significant effects on the ERICE changes (Appendix Fig. 14d, and Figs. 2d and 3b). Therefore, it is necessary to take into account the investment and the $R \& D$ behaviors of enterprises when further examining the drivers of the ERICE changes.

Drivers' changes of different scales at continuous four stages

\section{Drivers of the macroeconomic scale}

As mentioned above, to further explore the characteristics and reasons behind the ERICE changes here, the entire studied period of 1998-2015 was divided into four stages by the "Five-Year Plan" and the decomposition results from each stage were compared as follows. For convenience, the end of the 9th "Five-Year Plan" (1998-2000) was designated as the first stage. Table 4 and Fig. 4 present the corresponding results and changing trends of each factor, respectively.

Output effect The output effect had the largest average annual contribution rate (33.212\%). It was much larger than the others (Table 4), and always had a positive effect in all four stages (Fig. 4). This means that the industrial output growth was the most prominent driving factor for ERICE growth. This finding is consistent with the results obtained above and the conclusions of most related studies (Ren et al. 2012; Shao et al. 2011,
2016).This was because energy is considered to be the most basic production factor and economic development is characterized by industrialization and urbanization, which induce substantial energy consumption and the corresponding increases of the ERICE (Ren et al. 2012; Shao et al. 2016). Therefore, the ERICE's rise is a concomitant outcome of the economic development and increasing industrial output of Jiangxi. For example, the industrial output of Jiangxi had an obvious upward trend with an increase of approximately 10.16 times from 69.12 billion RMB in 1998 to 771.31 billion RMB in 2015. Its average annual growth rate during this period was $15.25 \%$ (Fig. 1a). As a result, the ERICE also increased (by 3.34 times) and climbed from $52.78 \mathrm{Mt}$ in 1998 to $176.37 \mathrm{Mt}$ in 2015 with an average annual growth rate of $7.35 \%$. Particularly, the ERICE's increases resulting from output were $2.55,67.96$, 163.52 , and $119.54 \mathrm{Mt}$ with average annual growth rates of $2.32 \%, 29.02 \%, 53.50 \%$, and $21.20 \%$ in the four stages, respectively, as shown in Fig. 2 and Appendix Tables 8 and 9. This is consistent with the changing trends of the contributions from the output to the ERICE's growth shown in Fig. 4.

Industrial structure effect The industrial structure adjustment presented an overall mitigating effect (the average annual contribution rate was $-7.804 \%$, as shown in Table 4) on the ERICE during the four stages, especially in 11th and 12th "Five-Year Plan" stages. This means that the industrial structure adjustment in Jiangxi was effective in mitigating $\mathrm{CO}_{2}$ emissions although it was not an obvious or even a driving effect in the initial 9th and 10th "Five-Year Plan" stages as shown in Fig. 4 and Table 4. This concept "adjustment" indicates that

Table 4 Contribution types and trends of the four stages and average annual contribution rates from various scale factors

\begin{tabular}{|c|c|c|c|c|}
\hline Scale & Type & Decomposition factor & Trend $^{\mathrm{a}}$ & $\begin{array}{l}\text { Average annual } \\
\text { contribution rate (\%) }\end{array}$ \\
\hline \multirow[t]{4}{*}{ Macro-economy } & Output effect & Output & ++++ & 33.212 \\
\hline & Structure effect & Energy structure & -+++ & 0.017 \\
\hline & & Industrial structure & ++-- & -7.804 \\
\hline & Intensity effect & Energy intensity & ---- & -11.652 \\
\hline \multirow[t]{3}{*}{ Micro--economy } & & Investment intensity & -+-- & 4.200 \\
\hline & & $\mathrm{R} \& \mathrm{D}$ intensity & +-+- & 9.537 \\
\hline & Efficiency effect & R\&D efficiency & -+-+ & -13.737 \\
\hline
\end{tabular}

a The sequence of trends was at the end of the 9th "Five-Year Plan" (1998-2000), the 10th "Five-Year Plan" (2000-2005), the 11th "FiveYear Plan" (2005-2010), and the 12th "Five-Year Plan"; + and - stand for positive and negative effects on the ERICE changes, respectively 


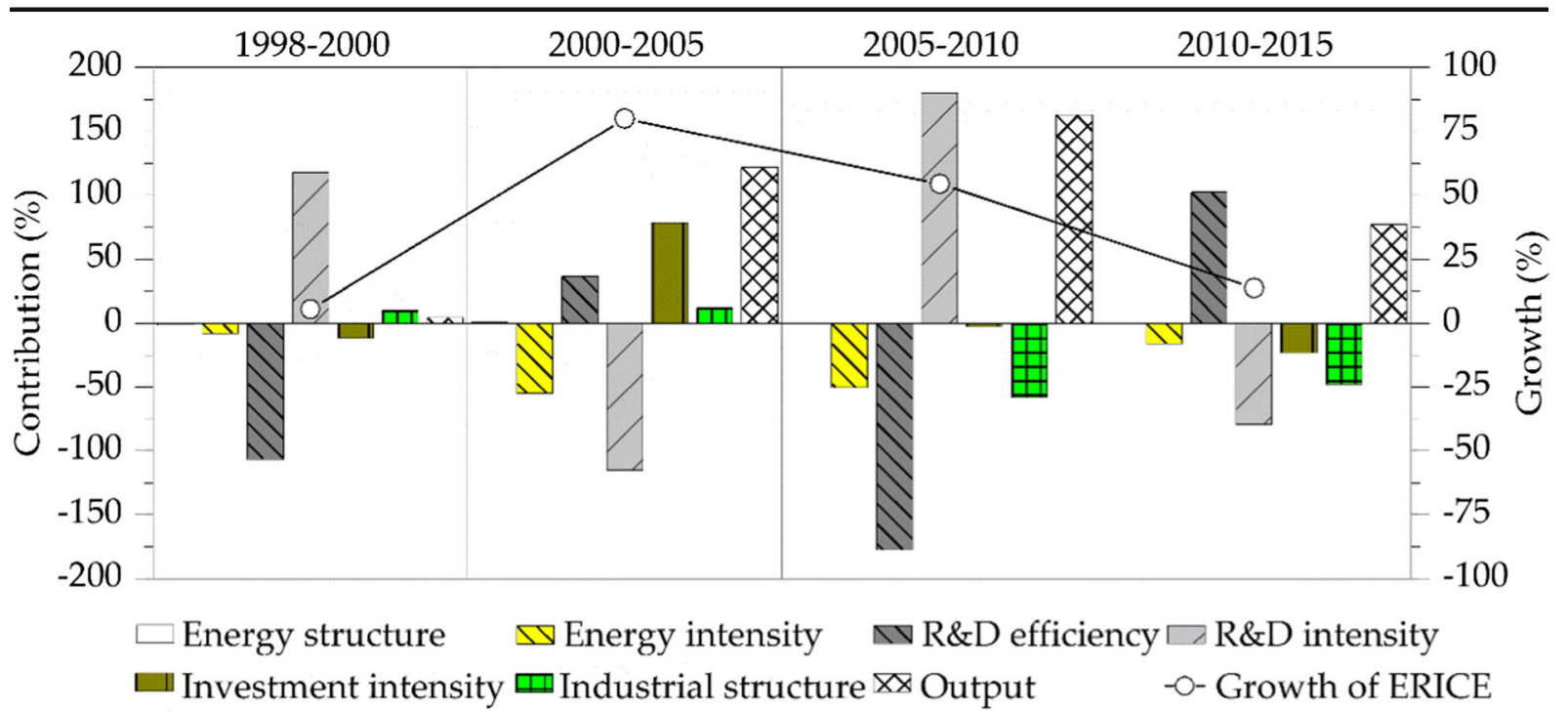

Fig. 4 Growth of the ERICE and contributions of its decomposition factors at four stages (i.e., the end of the 9th "Five-Year Plan" (19982000), the 10th "Five-Year Plan" (2000-2005), the 11th "Five-Year Plan" (2005-2010), and the 12th "Five-Year Plan" (2010-2011))

production resources were reallocated among industrial sectors with different technologies, efficiencies, and profits, thus inducing the changes of output share among the different sectors (Ren et al. 2012). According to neoclassical growth theory, structural adjustment is an important source of sustainable growth and a radical approach to transform the development pattern (Ren et al. 2012; Shao et al. 2011, 2016). Similarly, here, we consider that the industrial structural adjustment is the flow of production factors between industrial sectors with low energy consumption and $\mathrm{CO}_{2}$ emissions. With the development and opening of the Honggutan new district since the beginning of the twenty-first century, Jiangxi's industrial structure has gradually been transformed from raw material processing and manufacturing with high energy use and high pollutant emissions to a new phase with a more reasonable industrial structure. In this new phase, high-tech industries with low energy use and $\mathrm{CO}_{2}$ emissions, such as photovoltaic, electronic, solar, and information technology, have rapidly developed in Jiangxi. As depicted in Fig. 5a, the output share of this low emission group continuously increased while that of the high emission group symmetrically decreased during 1998-2015. Although the share of the former had slight decreases in 2003 and 2011, its share continued to rise from $21.50 \%$ in 1998 to $38.52 \%$ in 2015 , with an annual average increase of approximately $3.49 \%$. Therefore, the contribution of industrial structure adjustment to mitigate the ERICE was effective and dominant overall. The ERICE changes resulting from the industrial structural adjustment were 4.98, 6.56,58.61, and $-73.73 \mathrm{Mt}$ with the average annual decrease rates of $4.88 \%, 1.81 \%,-7.46 \%$, and $-7.19 \%$ in the four stages, respectively, as shown in Figs. 2 and 4 and Appendix Tables 8 and 9. This indicates that production resource reallocation among different sectors could drive the reduction of the ERICE and that a structural bonus also existed in Jiangxi over the long run.

Energy structure effect The effect of the energy structure was the weakest and could almost be neglected $(0.017 \%$, Table 4). Most relevant studies also drew similar conclusions and argued that it could be attributed to the coal-dominated energy resources and consumption structures in China (Ren et al. 2012; Shao et al. 2011, 2016). The $\mathrm{CO}_{2}$ emission coefficient of coal is higher than those of oil and gas. Hence, unlike other countries or regions, the long-term coal-dependent energy structure determined that most energy-related $\mathrm{CO}_{2}$ emissions in the Jiangxi Provence of China have come from coal burning. As depicted in Fig. 5b, the share of coal-type fuel use had decreased slightly from $73.3 \%$ in 1998 to $66.8 \%$ in 2015 . This implies that although the energy consumption structure in Jiangxi, to some extent, has been improved, the coal-type fuel is still the main source of Jiangxi's ERICE. Particularly, the average annual ERICE changes resulting from energy structural adjustments were $-0.39,0.14,0.03$, and $0.10 \mathrm{Mt}$ at the four stages, respectively (Appendix Table 8). This indicates that the impact of the energy 


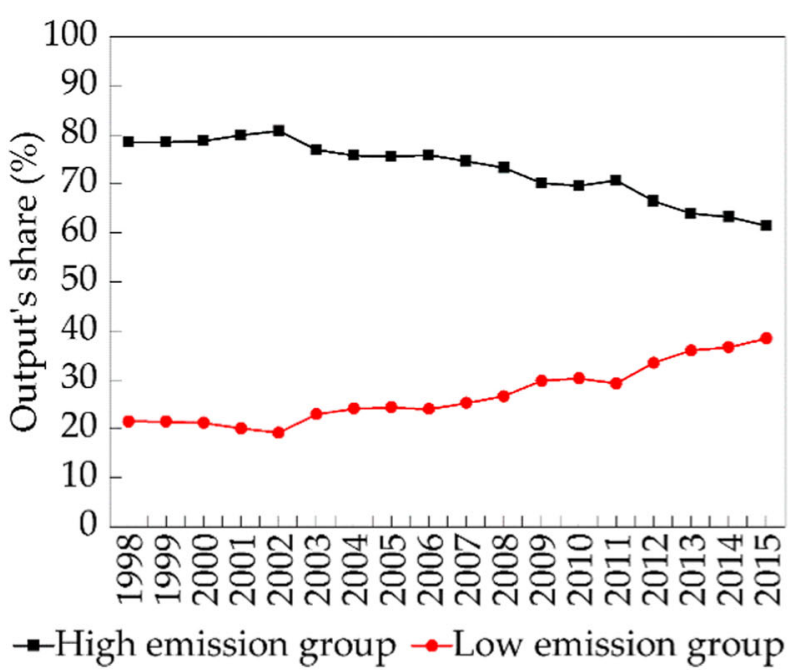

(a)

Fig. 5 a Output share's change of the high and low emission groups in Jiangxi (according to the ranking of the annual average ERICE over the period of 1998-2015, the high emission group

structural adjustment on the ERICE was relatively marginal. In fact, it is also difficult to mitigate the ERICE by altering the traditional coal-dominant energy structure in Jiangxi over the short term. In other words, the low-carbon pathway of energy structure adjustment requires a longer time and more effort.

Energy intensity effect The energy intensity has always had a mitigating effect on the ERICE (Fig. 4 and Table 4). The energy intensity had a slight mitigating effect on the ERICE during the first stage (1998-2000). This effect increased obviously in the second and third stages (2000-2005, 2005-2010). The average annual contribution rate of energy intensity to the ERICE was $-11.652 \%$. This means that the mitigation of Jiangxi's ERICE is largely dependent upon the decline of the energy intensity, which implies that an improvement of energy efficiency or level of technology. This is consistent with the finding of most of the related studies (Ren et al. 2012; Shao et al. 2011, 2016). The energy intensity of the entire industry in Jiangxi had an obvious decrease from 2.09 tce $/ 10^{4} \mathrm{RMB}$ in 1998 to 0.77 tce $/ 10^{4} \mathrm{RMB}$ in 2015 , which means that there was a continuous improvement of the energy efficiency.

As expected, the energy intensity had a visible mitigating effect on the ERICE in most years. However, in some ambiguous years, e.g., 2001, 2003, and 2015, the energy intensity also had a decline,

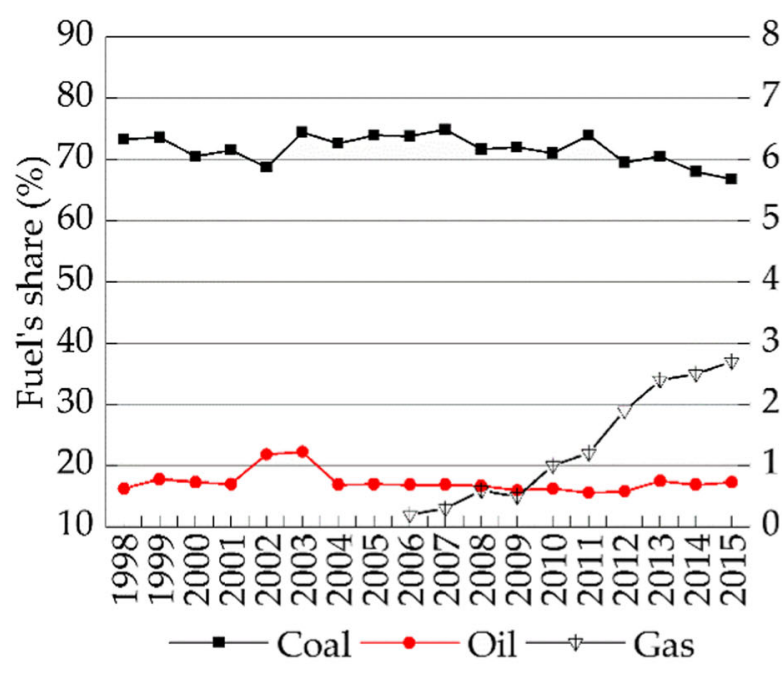

(b)

corresponds to the top half of the subsectors, and low emission group to the lower half of the subsectors). b Fuel share's change of the ERICE for the entire industry of Jiangxi

but the decline induced a promotional effect on the ERICE (Table 3). The paradox could be clarified by the following two aspects. First, following related studies (Ren et al. 2012; Shao et al. 2011, 2016), the impact of the energy intensity on $\mathrm{CO}_{2}$ emissions implicated an industrial structure effect, i.e., the energy intensity change of the largest $\mathrm{CO}_{2}$ emission subsector largely determined the influential direction of energy intensity of the entire industry on the ERICE. With respect to Jiangxi, the average annual ERICE of S33 (production and supply of electric power and heat power, Table 2) was $34.07 \mathrm{Mt}$ and this was much larger than the values of the other sectors, with a nearly $30 \%$ share of the total ERICE. The trend of S33's energy intensity change was very close to that of the multiplicative decomposition index of the energy intensity factor (Fig. 6). This indicates that the influential direction of the energy intensity on the ERICE changes largely depends on S33's energy intensity change. Second, the rebound effect mentioned above could be used to illuminate this "paradox". In these years, the energy intensity declined, which means that the energy efficiency had a certain increase. So, if the investment and R\&D activities were targeting production expansion, then the energy consumption and carbon emissions were added and augmented. Thus, a promotional effect on the ERICE appeared. Some scholars (Ren 
Fig. 6 Trends of the energy intensity change rate of the $\mathrm{S} 33$ subsector and multiplicative decomposition index of the energy intensity factor

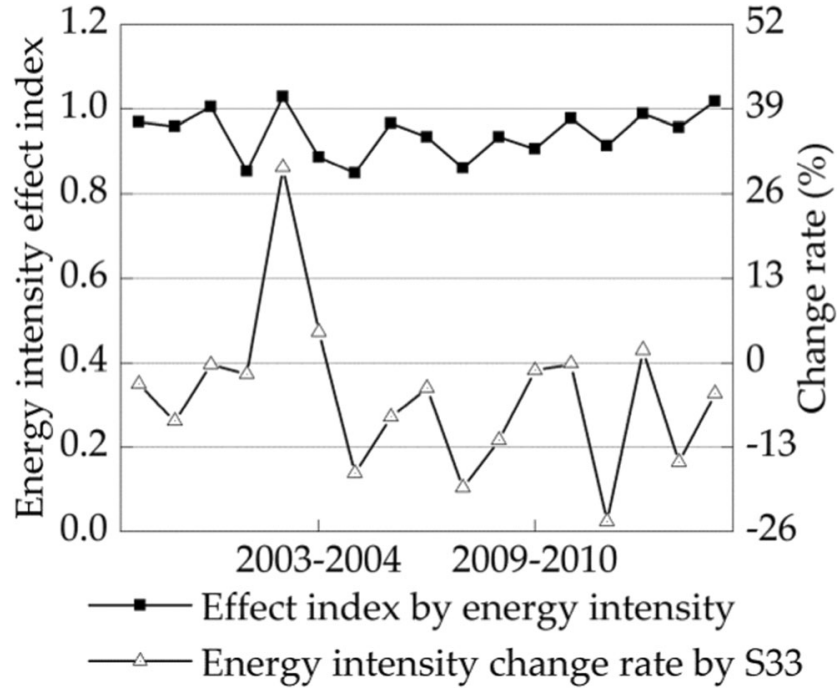

expenditure to represent the technology progress indicator. For decomposition convenience, here, we built two indicators ( $R \& D$ intensity and $R \& D$ efficiency) to jointly reflect the effect of the $R \& D$ expenditures. In other words, the R\&D effect was divided into a R\&D intensity effect and a R\&D efficiency effect.

Investment intensity effect The investment intensity had an overall promotional effect on the ERICE of Jiangxi (4.200\%, Table 4). The average annual ERICE changes induced by the investment intensity were $-2.19,8.74,-0.54$, and -7.19 Mt with the corresponding change rates of $-4.08 \%$, $15.59 \%,-0.43 \%$, and $-3.91 \%$ for the four stages (Figs. 2 and 4, and Appendix Tables 8 and 9), respectively. This indicates that there was a duality and an indirect improvement trend of its impact on the ERICE of Jiangxi. As depicted in Figs. 7 and 8 , the investment amount of Jiangxi's entire industry experienced a steady upward trend, but the evolution of investment intensity was irregular. The increase in the absolute investment amount meant a new round of output growth, which could or could not cause a relevant increase of the energy demand and the ERICE. On one hand, the increasing investment intensity could augment the ERICE through productivity expansion. On the other hand, it could improve energy utilization efficiency in the production processes to partially abate the ERICE through the upgrading production equipment. For example, some scholars (Ren et al. 
Fig. 7 Trends of the R\&D investment and fixed asset investment of the entire industry of Jiangxi

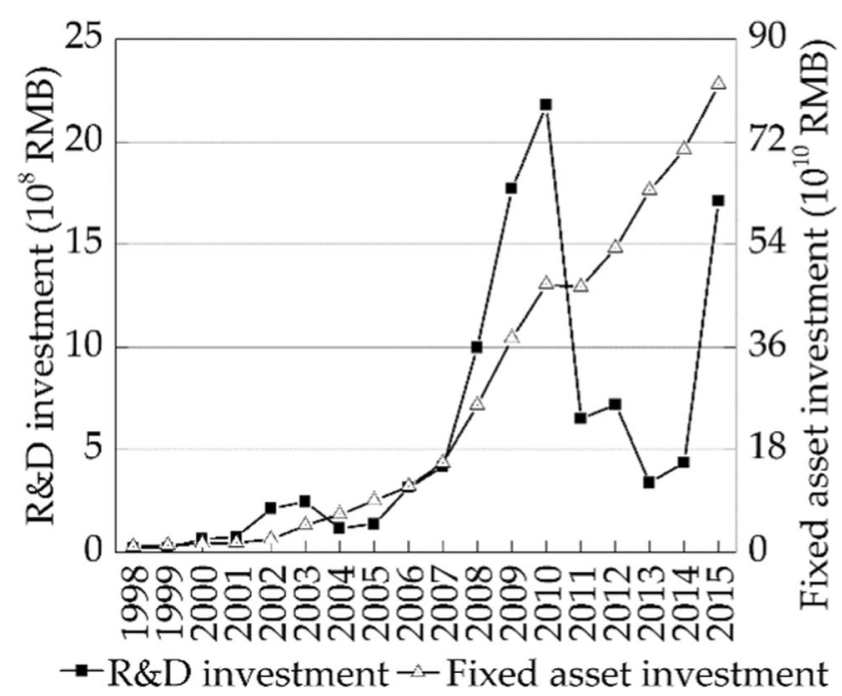

emission-reduction policy. This finding is consistent with the fact of the social-economic development in Jiangxi. In the end, the S33's investment intensity change could, to some extent, explain the direction change of the investment intensity effect on the ERICE. This was because the S33's change rate and effect index had very similar trends, although the latter had a more intensive fluctuation as depicted in Fig. 8.

$R \& D$ intensity effect The actual contribution of $\mathrm{R} \& \mathrm{D}$ activities to reduce the ERICE largely depends on whether R\&D activities were typically targeted at energy saving and emission reduction. Therefore, like the investment intensity, R\&D intensity and its induced technological progress could bring either a positive or a negative effect
Fig. 8 Trends of the investment intensity change rates of S33 and the multiplicative decomposition index of the investment intensity effect on the ERICE

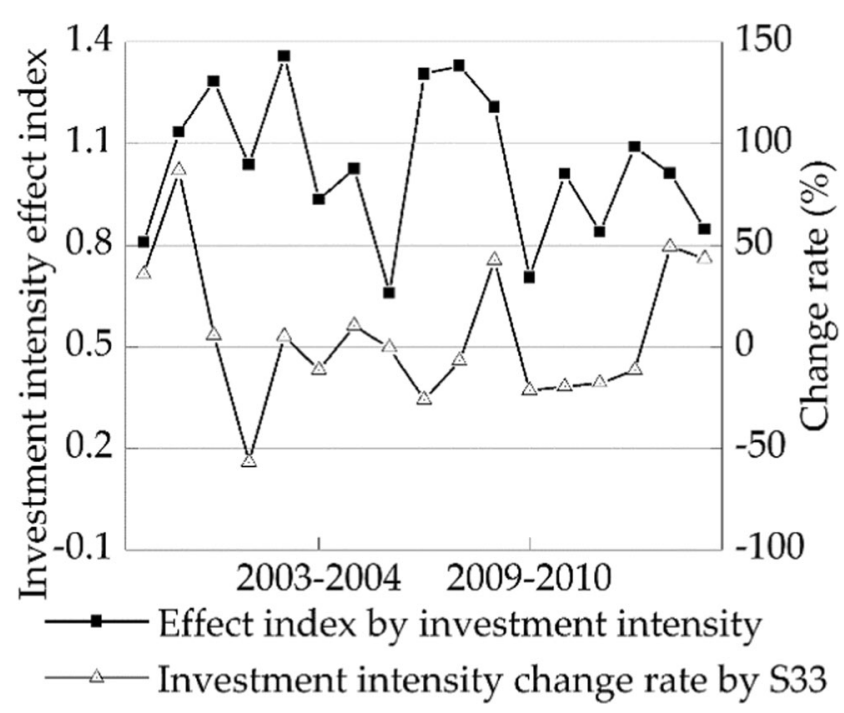


on mitigating the ERICE. If the R\&D activities were mainly made to develop energy-saving and emissionreduction technologies or cleaner production technologies, then the induced technological progress would promote energy efficiency, carbon productivity, and the utilization of renewable-energy sources to facilitate the abatement of $\mathrm{CO}_{2}$ emissions. In this case, the technological progress was entitled as green technological progress, which is regarded as the permanent driving force of energy saving and emission reduction (Ren et al. 2012; Shao et al. 2011, 2016). Conversely, if the R\&D activities were mainly exerted to develop new products and improve the productivity of input factors, especially physical capital, then the induced technological progress would cause the expansion of production and increases of the input factors, including energy. This goes against the achievement of energy saving and emission reduction. As expected, the R\&D intensity had a mitigating effect on the ERICE in some years, but it also had a positive effect in some other years (Table 3 and Fig. 2). During the four stages, the R\&D intensity had an obvious fluctuating effect on the ERICE. Particularly, the average annual ERICE changes resulting from the R\&D intensity effect were $30.88,-12.79,36.13$, and $-24.59 \mathrm{Mt}$ (Fig. 2 and Appendix Table 8), respectively. The reason behind the changes can be found in the comparison between the two trends of R\&D intensity change rates of S33 and that of the multiplicative decomposition index of the entire R\&D intensity (Fig. 9). As the largest ERICE subsector, S33's R\&D intensity change, to some extent, determined the influential direction of entire R\&D intensity on the ERICE.

Fig. 9 Trends of the R\&D intensity change rates of S33 and the multiplicative decomposition index of the R\&D intensity effect on the ERICE
In fact, the R\&D intensity itself also experienced similar but smaller fluctuations. It increased from $0.21 \%$ in 1998 to $0.41 \%$ in 2000 , then, decreased to $0.15 \%$ in 2005 , with a peak value in 2002 . After that, the R\&D intensity increased to $0.46 \%$ in 2010 and decreased again to $0.21 \%$ in 2015 (Fig. 10). The total R\&D expenditure had relatively obvious fluctuations and a total growth from 22.01 million RMB in 1998 to 1.71 billion RMB in 2015 (Fig. 7). However, at the same time, the fixed asset investment had a steady increase from 10.60 billion RMB in 1998 to 820.67 billion RMB in 2015 and had no obvious fluctuations (Fig. 7). The difference between the increase rates of these two indices was not obvious, as the fluctuations of the $R \& D$ intensity were small (Fig. 10). However, so far, a satisfactory explanation of the R\&D intensity effect on the ERICE has not been determined. For example, the total contribution of the R\&D intensity to the ERICE was a positive $162.13 \%$ during the period of 1998-2015 (Table 3). This would be much clearer if the $R \& D$ efficiency and the R\&D intensity were put together for a comprehensive analysis.

$R \& D$ efficiency effect The average annual ERICE changes resulting from the R\&D efficiency effect were $-28.69,4.05,-35.59$, and $31.78 \mathrm{Mt}$ with the corresponding change rates of $-32.34 \%, 6.12 \%,-15.15 \%$, and $32.26 \%$ at the four stages (Figs. 2 and 4; Appendix Tables 8 and 9), respectively. Such results also imply an unstable effect of the R\&D efficiency on the ERICE. As discussed above, this factor is closely related to the focus of the R\&D effort from industrial enterprises,

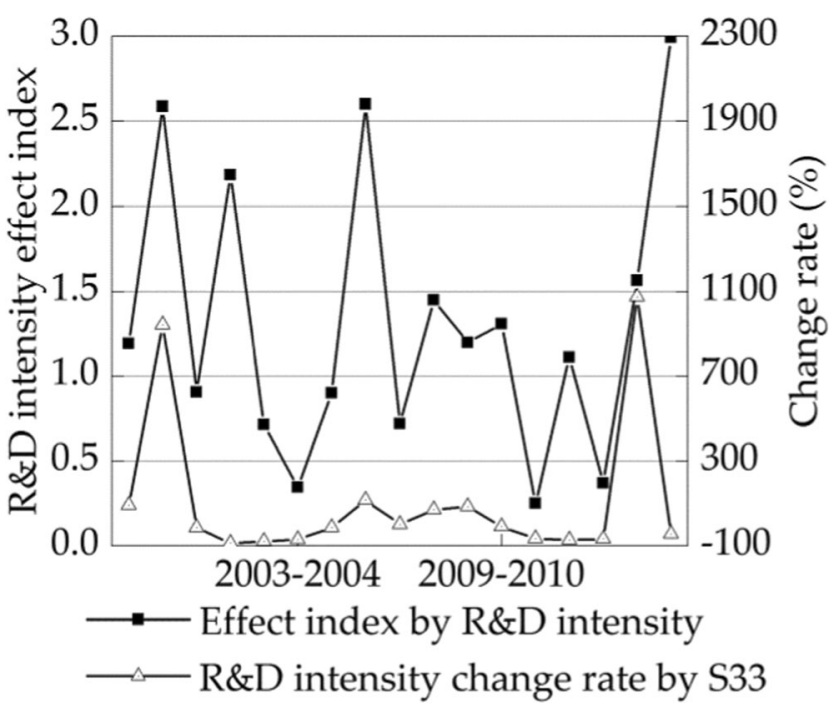


Fig. 10 Trends of the R\&D intensity, the investment intensity, and the R\&D efficiency of entire industry in Jiangxi

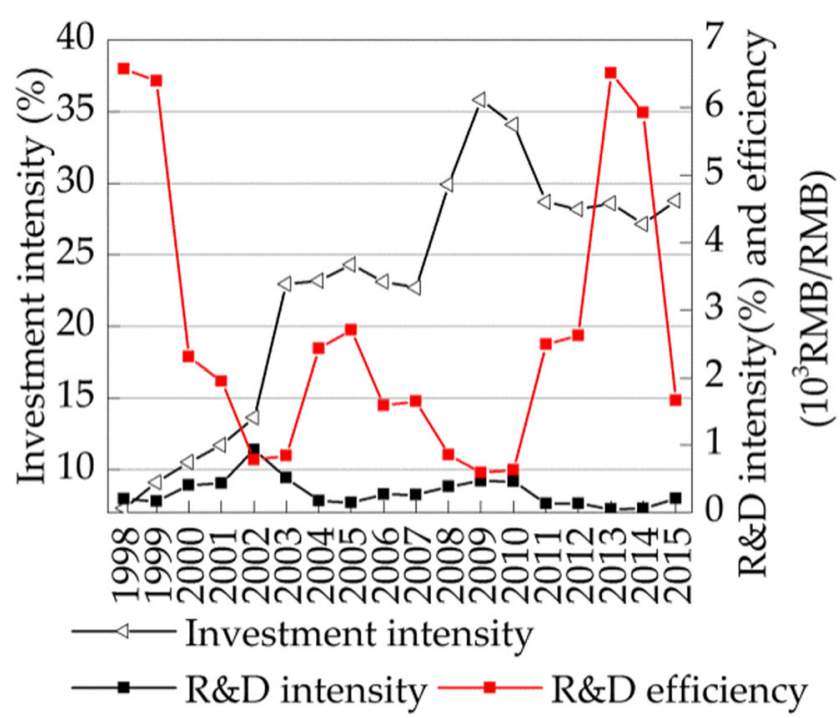

R\&D intensity (Fig. 10). For example, during the first stage (1998-2000), the contribution of the R\&D intensity to the ERICE was obviously positive, but the corresponding contribution of the R\&D efficiency was evidently negative (Table 4 and Fig. 4). The positive effect of the R\&D intensity means that the R\&D expenditures of Jiangxi might have been mainly exerted to develop new technology and improve the utilization efficiency for energy savings and emission reductions during 1998-2000. Thus, the R\&D expenditures used to expand products' amount were smaller and smaller. The corresponding output and the ERICE were also smaller and smaller. Therefore, the mitigating effect of the R\&D efficiency on the ERICE was more and more obvious
Fig. 11 Trends of the R\&D efficiency change rates of S33 and the multiplicative decomposition index of the R\&D efficiency effect on the ERICE

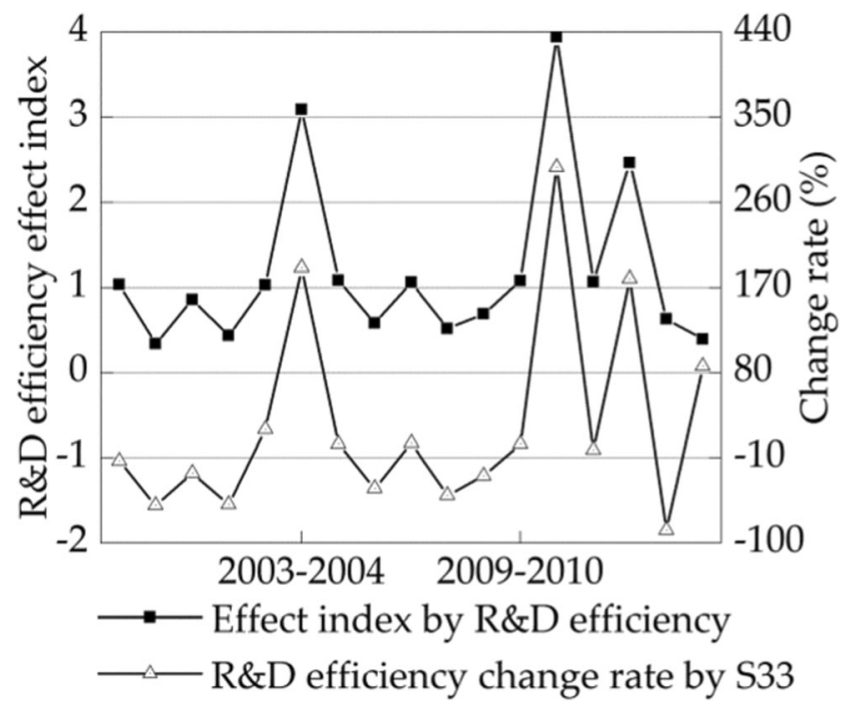


(the negative effect of the R\&D efficiency). Then, it can also be seen in Table 3 that the total contributions of the R\&D intensity and the R\&D efficiency were $162.13 \%$ and $-233.52 \%$, respectively. The average annual contribution rates of these two factors were $9.537 \%$ and $13.737 \%$ (Table 4), respectively. This means that the aggregated R\&D effect (intensity effect and efficiency effect) would still be mitigating (negative, 162.13$233.52 \%=-71.39 \%, 9.537-13.737 \%=-4.200 \%$ ) to the ERICE. In other words, the technological progress reflected by these two indicators is still a prominent factor for abating the ERICE in Jiangxi. This is consistent with most of the related studies (Ren et al. 2012; Shao et al. 2011, 2016). Thus, we can say that the R\&D intensity and R\&D efficiency should be considered comprehensively when decomposing the ERICE changes, because they can commonly reflect the direction of the $R \& D$ activities or technological progress.

\section{Strategies for reducing the ERICE}

Based on these results discussed above, some particular strategies or measures for reducing the ERICE of Jiangxi Province are proposed as follows. These strategies can also undoubtedly improve the energy use efficiency of the local government. First, industrial output is the most prominent driving force for the ERICE growth in this region (33.212\%), but it is not feasible to abate the ERICE by decelerating industrial development and inhibiting the need for a better life for people. Therefore, the Jiangxi's government has to seek a trade-off between economic development and emission reductions. Emission-reduction policies should contribute to counteract the output effect by activating compositional and technological effects. In other words, Jiangxi also has to experience a structural and technological emission reduction process. This goal can come true only by transforming the pattern of Jiangxi's economic growth. For example, a circular economy should be promoted so that the total consumption of fossil fuels and raw materials, and the corresponding ERICE can be minimized. As a result, the energy use efficiency of the local government can also be greatly improved.

Then, following output, R\&D intensity and investment intensity also extremely drive the growth of the ERICE. Their average annual contribution rates were $9.537 \%$ and $4.200 \%$, respectively. In addition, their promotional effects had obvious fluctuations. However, like the output, it is also not feasible to abate the ERICE by decelerating the corresponding activities of these two drivers. Thus, the same routes or measures for improving the energy use efficiency of Jiangxi can also be used, as discussed above, to reduce the regional ERICE.

In addition, the effect of the energy structure on the ERICE is also positive, and it is the weakest factor with an average annual contribution rate of $0.017 \%$. This indicates that the energy structure adjustment toward improving energy efficiency to abate the ERICE is still an arduous process in Jiangxi in the short term. However, the energy structure adjustment has a large potential for improving the energy use efficiency of the local government through a reasonable design of green energy policies, etc. (Shao et al. 2016). In other words, we cannot ignore the potential role of energy structure optimization in improving energy efficiency and reducing the ERICE's absolute amount in the long run.

However, the R\&D efficiency of industrial enterprises plays a crucial role in mitigating the ERICE $(-13.737 \%)$. As mentioned above, the enterprises' R\&D investment decisions also often tended to focus on expanding production amount, which went against the emission reduction efforts. Therefore, the government should enhance the promotional effect of some fiscal policies so that enterprises will pay more attention to converting their investment direction towards energy savings and emission reductions. For example, some regulatory policy instruments, such as a carbon-reduction liability, carbon emission audits, and carbon labels could be implemented to encourage industrial firms to improve their energy efficiency and carbon emission performance.

The energy intensity is also one of the key factors in abating the ERICE in Jiangxi (-11.625\%), which was slightly less than the expected value $(11.652 \%<$ $13.737 \%$ ), due to the rebound effect. Thus, in Jiangxi, the effects of energy intensity could bring desired emission-reduction only if the rebound effect was effectively restricted. Therefore, a more rational policy design should fully consider the potential rebound effect and restrict it through a market-oriented policy mix, especially the marketization reform of energy pricing. To sum up, as found in the studied period of 1998-2015, to reduce the energy intensity unceasingly of the entire industry to improve the corresponding energy use efficiency, while inhibiting the possible rebound effect, will also serve as a long-term development strategy for the local government. 
Fig. 12 Dynamics' changes of energy consumption of industrial subsectors in Jiangxi

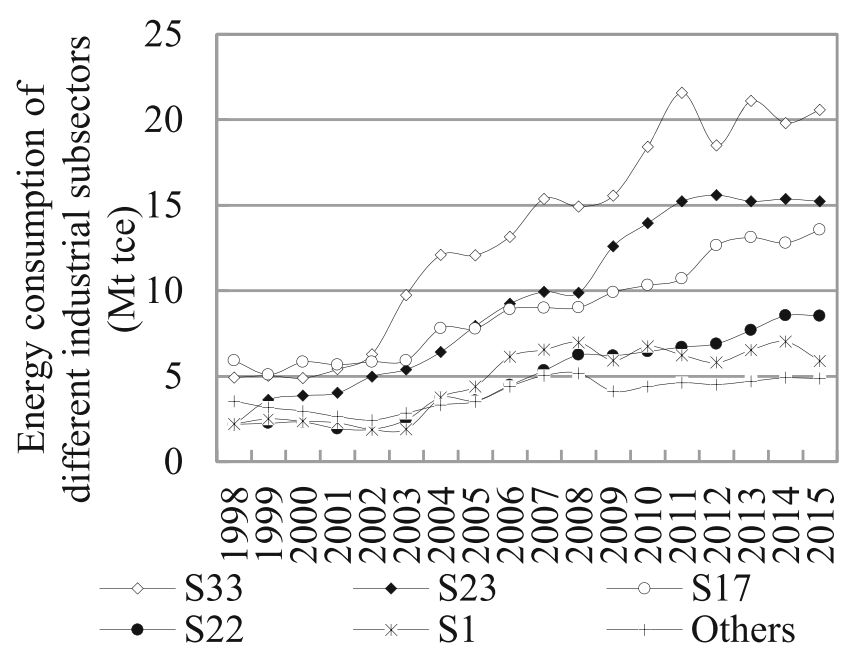

Jiangxi, the data dynamic changes of the energy consumption in different subsectors were drawn and are shown in Fig. 12. The top five energyintensive subsectors in Jiangxi were S33, S23 (Smelting and Pressing of Ferrous Metals), S17 (Processing of Petroleum, Coking, Processing of Nuclear Fuel), S22 (Manufacture of Non-metallic Mineral Products), and S1 (Mining and Washing of Coal). The highest energy-intensive subsector was S33. These results are consistent with those discussed above. Thus, these five energy-intensive subsectors should be given priority when designing related ERICE reduction policies. Similarly, the changes of different types of fuels used in subsector S33 were also drawn and are shown in Fig. 13. It can easily be seen that the energy consumption of

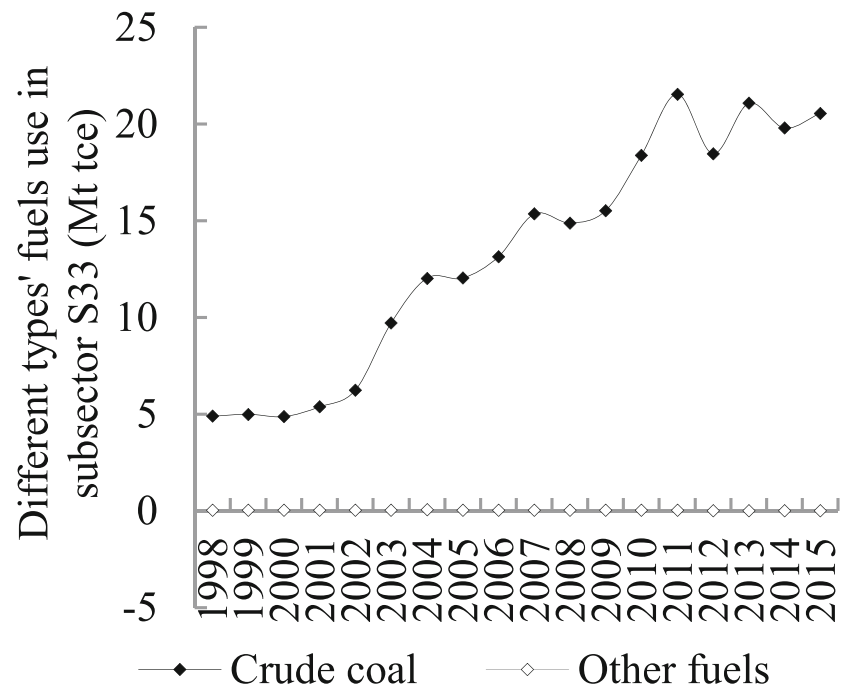

Fig. 13 Different types' fuels use in subsector S33 
S33 was almost entirely composed of crude coal use and the use of other fuels was almost equal to zero (Fig. 13). In reality, the energy consumptions of subsectors S23, S17, S22 and S1 had a structure similar to that of S33 but were omitted for saving space. Therefore, in Jiangxi, the government should positively implement the utilization of clean-coal technology, greatly promote the development of renewable-energy, etc. to ultimately improve the efficiency of energy use. These results are also consistent with those discussed above.

\section{Conclusions}

So far, there have been few scientists who have analyzed the ERICE drivers from both the macroeconomic and the microeconomic scales, especially for underdeveloped regions. Hence, in this investigation, taking the Jiangxi Province of China as the study case, we computed the ERICE and decomposed its drivers from both of these scales by using an extended LMDI model. In this model, we not only decomposed the ERICE changes of Jiangxi over the period of 1998-2015 into four conventional factors from the macroeconomic scale but also introduced specifically three novel factors from the microeconomic scale. Particularly, the macroeconomic factors were output, industrial structure, energy intensity and energy structure. In addition, the microeconomic factors were investment intensity, $R \& D$ intensity and $\mathrm{R} \& \mathrm{D}$ efficiency.

The numerical results showed: among the promotion factors of the ERICE, output growth was the most prominent driving force due to rapid industrialization and urbanization in the most recent 20 years. Its average annual contribution rate was $33.212 \%$. Following this factor, $R \& D$ intensity had the next highest effect on the growth of the ERICE. The next promotion factor was investment intensity. Their promotional effects had obvious fluctuations and the average annual contribution rates were $9.537 \%$ and $4.200 \%$, respectively. The effect of the energy structure on the ERICE was also positive, and it was the weakest factor with an average annual contribution rate of $0.017 \%$. In contrast, the R\&D efficiency presented the most obvious mitigating effect on the ERICE $(-13.737 \%)$. Energy intensity and industrial structure followed this factor. Their average annual contribution rates were $11.652 \%$ and $-7.804 \%$, respectively.
Thus, it was found that, to improve the energy efficiency of Jiangxi and reduce the ERICE, the local government had to transform the pattern of economic growth, e.g., a circular economy should be promoted. Then, people could not ignore the potential role of energy structure optimization over the long run. Third, some regulatory policy instruments related to $R \& D$ investment, such as carbonreduction liability, carbon emission audits, and carbon labels could be implemented to encourage industrial firms to improve their energy efficiency and carbon emission performance. Fourth, as in the studied period of 1998-2015, reducing the energy intensity unceasingly while inhibiting the possible rebound effect should serve as a longterm strategy for the local government. The industrial development of light and advanced manufacturing with low energy consumption and high added values should be promoted. Meanwhile, those energy-intensive industries with obsolete technologies and efficiencies should be gradually phased out. Particularly, the top five energyintensive subsectors (S33, S23, S17, S22, and S1) should be given priority when designing related ERICE reduction policies. Last, the government should positively implement the utilization of clean-coal technology and greatly promote the development of renewable-energy, etc.

Acknowledgments We thank the editors and anonymous reviewers for providing helpful suggestions, and Dr. Zhihai Gong for help in revising the manuscript twice.

Authors' contributions Junsong Jia and Chundi Chen designed the research; Huiyong Jian performed it and analyzed the result with the help of Dongming Xie; Junsong Jia wrote almost all the text of first submission with the help of Zhongyu Gu; Zhihai Gong completed the second and third revisions under the direction of Junsong Jia. All authors read and approved the final manuscript.

Funding information The Chinese National Science Foundation $(41001383,71473113,31360120,51408584)$, Natural Science Foundation of Jiangxi (20151BAB203040), and Scientific or Technological Research Project of Jiangxi's Education Department (GJJ14266) provided financial support.

\section{Compliance with ethical standards}

Conflict of interest The authors declare that they have no conflict of interest. 


\section{Appendix}

Fig. 14 Multiplicative decomposition results of Jiangxi's ERICE changes in the three "Five-Year Plan" periods and the entire period $\left(\Psi \mathrm{C}_{\mathrm{f}}, \Psi \mathrm{C}_{\mathrm{ES}}, \Psi \mathrm{C}_{\mathrm{EI}}\right.$, $\Psi \mathrm{C}_{\mathrm{RE}}, \Psi \mathrm{C}_{\mathrm{RI}}, \Psi \mathrm{C}_{\mathrm{II}}, \Psi \mathrm{C}_{\mathrm{IS}}$, and $\Psi \mathrm{C}_{\mathrm{O}}$ denoted the effects of emission coefficient, energy structure, energy intensity, R\&D efficiency, R\&D intensity, investment intensity, industrial structure, and output on the ERICE changes, respectively). a 2000-2005. b 2005-2010. c 2010-2015. d 1998-2015

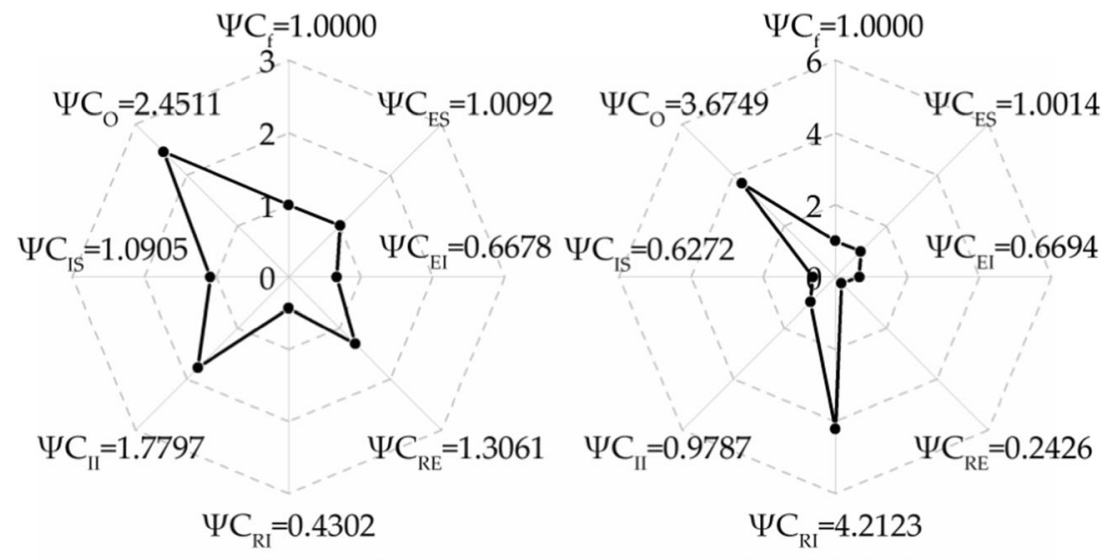

$\begin{array}{ll}\text { (a) } 2000-2005 & \text { (b) } 2005-2010\end{array}$

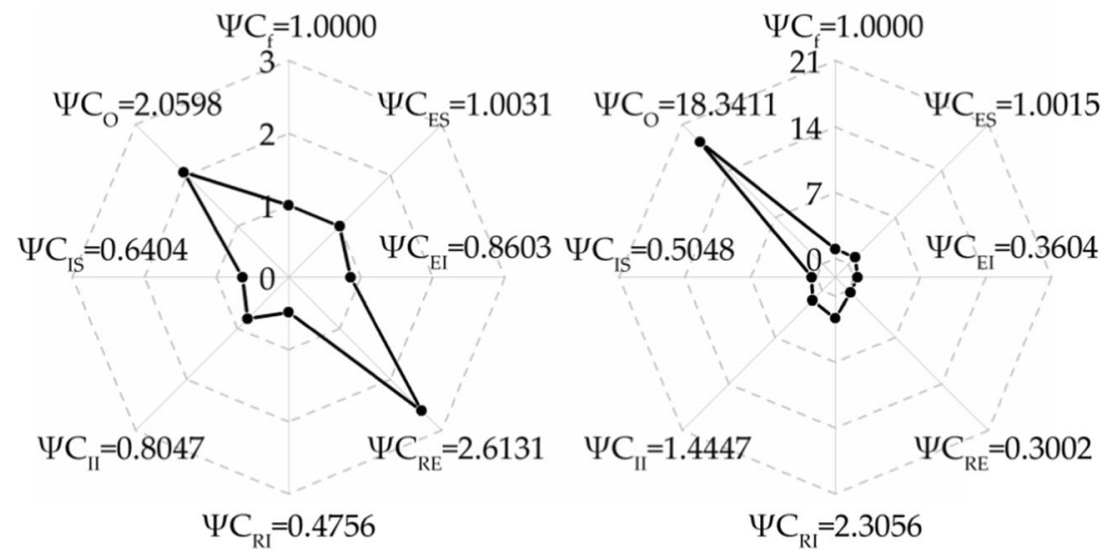

$\begin{array}{ll}\text { (c) } 2010-2015 & \text { (d) } 1998-2015\end{array}$

Table 5 Emission coefficients of nine energy sources

\begin{tabular}{|c|c|c|c|c|}
\hline Fuel & $\begin{array}{l}\text { Net calorific } \\
\text { value }(\mathrm{TJ} / \mathrm{Gg})^{\mathrm{a}}\end{array}$ & $\begin{array}{l}\text { Carbon } \\
\text { content }(\mathrm{kg} / \mathrm{GJ})^{\mathrm{a}}\end{array}$ & $\begin{array}{l}\text { Carbon } \\
\text { oxidation rate }(\%)^{\mathrm{b}}\end{array}$ & $\begin{array}{l}\text { Emission coefficient } \\
\text { (unit: } 10^{4} \mathrm{t} \mathrm{CO}_{2} / 10^{4} \\
\text { t or } 10^{4} \mathrm{t} \mathrm{CO}_{2} / 10^{8} \mathrm{~m}^{3} \text { (for gas)) }\end{array}$ \\
\hline Raw coal & 20.908 & 26.1 & 91.6 & 1.8300 \\
\hline Cleanedcoal & 26.344 & 25.8 & 98.0 & 2.4423 \\
\hline Other cleaned coal & 8.400 & 25.8 & 99.8 & 0.7890 \\
\hline Coke & 28.435 & 29.2 & 92.8 & 2.8252 \\
\hline Crude oil & 41.816 & 20.0 & 97.9 & 3.0021 \\
\hline Gasoline & 43.070 & 18.9 & 98.0 & 2.9251 \\
\hline Kerosene & 43.070 & 19.6 & 98.6 & 3.0520 \\
\hline Diesel & 42.652 & 20.2 & 98.2 & 3.1022 \\
\hline Fuel oil & 41.816 & 21.1 & 98.5 & 3.1866 \\
\hline
\end{tabular}

\footnotetext{
${ }^{a}$ The value is from the IPCC recommended value

${ }^{\mathrm{b}}$ The value is from Ren et al. (2012) and Shao et al. $(2011,2016)$ ); $1 \mathrm{TJ}=10^{3} \mathrm{GJ}=10^{12} \mathrm{~J}$
} 
Table 6 The ERICE results of various subsectors in Jiangxi during 1998-2015 (unit: $10^{4}$ t)

\begin{tabular}{|c|c|c|c|c|c|c|c|c|c|}
\hline Sector & 1998 & 1999 & 2000 & 2001 & 2002 & 2003 & 2004 & 2005 & 2006 \\
\hline S1 & 565.00 & 641.18 & 607.47 & 583.03 & 479.80 & 488.14 & 964.73 & 1128.06 & 1578.52 \\
\hline $\mathrm{S} 2$ & 0.08 & 0.16 & 0.12 & 0.05 & 0.06 & 0.28 & 4.48 & 4.67 & 13.63 \\
\hline S3 & 10.38 & 9.80 & 9.17 & 7.65 & 7.51 & 6.22 & 14.61 & 7.89 & 12.23 \\
\hline S4 & 39.59 & 35.13 & 38.55 & 25.47 & 18.81 & 43.20 & 5.53 & 18.38 & 41.43 \\
\hline S5 & 2.11 & 1.50 & 0.71 & 0.85 & 0.25 & 12.01 & 12.17 & 10.95 & 17.63 \\
\hline S6 & 39.63 & 42.73 & 30.18 & 20.89 & 19.84 & 27.34 & 66.53 & 88.49 & 136.94 \\
\hline S7 & 8.65 & 11.66 & 12.37 & 11.63 & 9.08 & 16.90 & 19.21 & 24.24 & 26.00 \\
\hline S8 & 3.08 & 3.80 & 4.00 & 5.66 & 5.24 & 4.87 & 5.80 & 6.32 & 11.95 \\
\hline S9 & 48.35 & 53.18 & 55.80 & 46.72 & 38.13 & 40.27 & 33.96 & 45.23 & 47.67 \\
\hline $\mathrm{S} 10$ & 0.64 & 0.38 & 0.10 & 0.25 & 0.21 & 0.23 & 0.84 & 4.96 & 6.75 \\
\hline S11 & 1.41 & 1.07 & 1.09 & 0.76 & 0.39 & 1.05 & 0.96 & 1.17 & 1.90 \\
\hline S12 & 28.48 & 27.36 & 30.55 & 31.16 & 28.74 & 19.73 & 23.72 & 17.41 & 15.28 \\
\hline S13 & 0.43 & 0.71 & 0.18 & 0.04 & 1.05 & 0.02 & 0.07 & 0.58 & 1.10 \\
\hline S14 & 71.99 & 82.38 & 86.12 & 79.77 & 45.32 & 33.18 & 36.97 & 30.53 & 130.23 \\
\hline S15 & 0.78 & 0.84 & 0.66 & 0.66 & 0.58 & 0.47 & 0.46 & 2.28 & 2.35 \\
\hline S16 & 0.10 & 0.09 & 0.21 & 0.00 & 0.43 & 0.31 & 0.12 & 0.84 & 0.87 \\
\hline S17 & 1365.63 & 1127.38 & 1276.90 & 1253.52 & 1297.17 & 1309.69 & 1770.47 & 1780.95 & 2040.51 \\
\hline S18 & 396.34 & 313.53 & 286.77 & 276.92 & 271.96 & 257.56 & 370.02 & 305.47 & 285.22 \\
\hline S19 & 43.67 & 33.50 & 31.42 & 26.01 & 28.45 & 50.68 & 41.52 & 46.94 & 47.39 \\
\hline S20 & 47.38 & 45.85 & 34.35 & 25.30 & 29.03 & 87.89 & 52.72 & 124.84 & 110.36 \\
\hline $\mathrm{S} 21$ & 5.33 & 10.47 & 5.00 & 10.54 & 4.66 & 5.64 & 13.28 & 12.42 & 12.75 \\
\hline $\mathrm{S} 22$ & 560.04 & 574.10 & 592.28 & 496.22 & 485.18 & 626.88 & 962.32 & 914.13 & 1144.62 \\
\hline S23 & 611.18 & 1009.26 & 1078.58 & 1121.91 & 1391.62 & 1509.55 & 1801.02 & 2219.96 & 2583.99 \\
\hline S24 & 65.14 & 61.83 & 60.17 & 58.91 & 57.39 & 66.61 & 80.28 & 77.49 & 121.17 \\
\hline $\mathrm{S} 25$ & 7.95 & 4.34 & 5.03 & 2.56 & 3.88 & 5.30 & 7.01 & 6.42 & 9.09 \\
\hline S26 & 22.82 & 12.71 & 11.65 & 6.60 & 8.06 & 5.29 & 16.12 & 7.84 & 11.20 \\
\hline S27 & 7.07 & 5.25 & 4.73 & 1.49 & 3.41 & 3.02 & 2.34 & 3.61 & 4.03 \\
\hline S28 & 14.22 & 16.12 & 14.93 & 14.10 & 19.97 & 18.48 & 19.69 & 22.20 & 22.39 \\
\hline S29 & 12.49 & 6.92 & 4.66 & 3.60 & 3.60 & 3.08 & 5.01 & 7.94 & 10.71 \\
\hline $\mathrm{S} 30$ & 5.09 & 2.00 & 1.67 & 1.57 & 1.32 & 1.01 & 0.57 & 1.39 & 2.82 \\
\hline S31 & 2.39 & 1.46 & 1.59 & 1.38 & 1.49 & 1.34 & 1.02 & 0.61 & 1.01 \\
\hline S32 & 25.42 & 23.40 & 23.98 & 11.25 & 10.49 & 12.07 & 4.52 & 7.24 & 7.19 \\
\hline S33 & 1261.90 & 1287.03 & 1253.06 & 1384.68 & 1606.54 & 2497.62 & 3094.22 & 3091.62 & 3371.06 \\
\hline S34 & 3.37 & 2.51 & 3.12 & 4.25 & 3.44 & 3.54 & 6.16 & 5.08 & 1.77 \\
\hline S35 & 0.14 & 0.94 & 0.17 & 0.14 & 1.52 & 0.14 & 0.19 & 0.27 & 1.45 \\
\hline Total & 5278.27 & 5450.54 & 5567.35 & 5515.52 & 5884.61 & 7159.60 & 9438.65 & $10,028.41$ & $11,833.19$ \\
\hline Sector & 2007 & 2008 & 2009 & 2010 & 2011 & 2012 & 2013 & 2014 & 2015 \\
\hline S1 & 1683.06 & 1794.37 & 1527.27 & 1738.72 & 1607.57 & 1485.18 & 1675.15 & 1798.05 & 1509.89 \\
\hline $\mathrm{S} 2$ & 13.80 & 16.53 & 12.28 & 15.32 & 14.57 & 13.33 & 15.33 & 12.45 & 10.51 \\
\hline S3 & 21.34 & 16.49 & 10.54 & 11.05 & 8.52 & 9.28 & 6.52 & 6.78 & 5.53 \\
\hline S4 & 48.99 & 70.17 & 69.86 & 52.72 & 34.59 & 34.54 & 138.04 & 132.16 & 103.89 \\
\hline S5 & 22.97 & 31.02 & 27.79 & 22.20 & 25.96 & 38.04 & 39.87 & 33.75 & 34.85 \\
\hline S6 & 155.24 & 196.29 & 165.98 & 164.24 & 171.18 & 170.79 & 80.14 & 80.13 & 91.15 \\
\hline S7 & 31.79 & 33.71 & 23.64 & 22.58 & 19.30 & 18.49 & 21.22 & 17.09 & 16.17 \\
\hline S8 & 4.57 & 3.31 & 3.54 & 3.25 & 3.19 & 3.32 & 3.94 & 2.24 & 1.67 \\
\hline
\end{tabular}


Table 6 (continued)

\begin{tabular}{|c|c|c|c|c|c|c|c|c|c|}
\hline S9 & 46.25 & 38.36 & 24.28 & 24.08 & 21.85 & 15.76 & 13.41 & 11.79 & 11.96 \\
\hline $\mathrm{S} 10$ & 7.14 & 7.48 & 5.86 & 7.46 & 3.83 & 5.23 & 4.84 & 3.81 & 3.37 \\
\hline S11 & 1.93 & 1.81 & 1.93 & 2.80 & 2.19 & 3.28 & 3.89 & 3.76 & 3.72 \\
\hline $\mathrm{S} 12$ & 15.08 & 13.19 & 9.28 & 6.83 & 4.20 & 2.52 & 2.60 & 2.02 & 1.62 \\
\hline $\mathrm{S} 13$ & 1.07 & 2.00 & 1.66 & 0.85 & 1.13 & 1.18 & 0.79 & 1.00 & 1.25 \\
\hline S14 & 129.93 & 122.40 & 85.74 & 116.54 & 115.73 & 111.62 & 113.09 & 156.24 & 161.60 \\
\hline S15 & 1.41 & 1.18 & 1.01 & 1.02 & 0.87 & 0.74 & 2.76 & 2.96 & 3.08 \\
\hline S16 & 1.25 & 1.34 & 1.16 & 1.32 & 2.07 & 3.23 & 5.00 & 4.43 & 3.45 \\
\hline S17 & 2086.20 & 2069.06 & 2278.69 & 2375.57 & 2515.89 & 2976.87 & 3089.27 & 3056.16 & 3186.74 \\
\hline S18 & 298.60 & 373.24 & 277.49 & 293.36 & 344.74 & 301.92 & 338.76 & 384.53 & 381.75 \\
\hline S19 & 51.13 & 51.87 & 37.60 & 39.25 & 37.68 & 42.93 & 39.80 & 41.05 & 45.22 \\
\hline $\mathrm{S} 20$ & 171.77 & 53.40 & 45.55 & 52.42 & 88.12 & 105.52 & 114.87 & 103.71 & 115.38 \\
\hline $\mathrm{S} 21$ & 18.96 & 21.13 & 20.28 & 19.04 & 13.01 & 12.67 & 13.08 & 13.42 & 15.03 \\
\hline S22 & 1365.23 & 1598.08 & 1588.27 & 1650.04 & 1717.04 & 1765.68 & 1968.24 & 2184.41 & 2182.47 \\
\hline $\mathrm{S} 23$ & 2789.40 & 2768.47 & 3531.28 & 3899.28 & 4264.32 & 4358.56 & 4259.93 & 4297.74 & 4255.43 \\
\hline $\mathrm{S} 24$ & 157.90 & 175.57 & 145.96 & 162.98 & 164.49 & 178.22 & 172.43 & 174.47 & 172.85 \\
\hline S25 & 9.83 & 11.49 & 9.41 & 8.76 & 7.79 & 7.63 & 7.15 & 7.34 & 7.44 \\
\hline S26 & 14.13 & 14.30 & 9.79 & 10.14 & 9.75 & 7.83 & 8.13 & 6.34 & 6.12 \\
\hline S27 & 4.72 & 4.65 & 4.97 & 4.40 & 4.02 & 5.82 & 6.38 & 8.43 & 9.37 \\
\hline S28 & 21.90 & 21.81 & 21.69 & 28.72 & 29.23 & 23.35 & 20.52 & 16.19 & 8.41 \\
\hline S29 & 9.72 & 16.00 & 14.15 & 16.39 & 14.71 & 20.09 & 17.85 & 16.41 & 14.21 \\
\hline S30 & 2.52 & 3.45 & 2.73 & 2.63 & 1.75 & 1.56 & 2.01 & 2.33 & 1.23 \\
\hline S31 & 1.17 & 1.07 & 0.23 & 0.42 & 0.35 & 0.10 & 0.09 & 0.07 & 0.13 \\
\hline S32 & 9.37 & 3.39 & 2.61 & 3.06 & 2.25 & 1.58 & 0.74 & 0.86 & 1.05 \\
\hline S33 & 3938.49 & 3820.28 & 3982.11 & 4718.22 & 5527.17 & 4734.72 & 5403.67 & 5074.55 & 5270.22 \\
\hline S34 & 1.94 & 1.95 & 0.37 & 18.09 & 19.64 & 0.44 & 0.31 & 0.30 & 0.29 \\
\hline S35 & 0.37 & 0.35 & 0.36 & 0.36 & 0.22 & 0.22 & 0.26 & 0.28 & 0.38 \\
\hline Total & $13,139.20$ & $13,359.20$ & $13,945.38$ & $15,494.11$ & $16,798.91$ & $16,462.24$ & $17,590.09$ & $17,657.22$ & $17,637.41$ \\
\hline
\end{tabular}

Table 7 Detailed multiplicative decomposition results of the ERICE changes

\begin{tabular}{|c|c|c|c|c|c|c|c|c|}
\hline Stage & $\Psi \mathrm{C}_{\mathrm{TOT}}$ & $\Psi \mathrm{C}_{\mathrm{ES}}$ & $\Psi \mathrm{C}_{\mathrm{EI}}$ & $\Psi C_{\mathrm{RE}}$ & $\Psi \mathrm{C}_{\mathrm{RI}}$ & $\Psi \mathrm{C}_{\mathrm{II}}$ & $\Psi \mathrm{C}_{\mathrm{IS}}$ & $\Psi \mathrm{C}_{\mathrm{O}}$ \\
\hline 1998-1999 & 1.0326 & 0.9880 & 0.9706 & 1.0380 & 1.1912 & 0.8088 & 1.1144 & 0.9663 \\
\hline 1999-2000 & 1.0214 & 0.9977 & 0.9598 & 0.3403 & 2.5876 & 1.1355 & 0.9850 & 1.0828 \\
\hline 2000-2001 & 0.9907 & 1.0021 & 1.0058 & 0.8608 & 0.9045 & 1.2844 & 1.0140 & 0.9693 \\
\hline 2001-2002 & 1.0669 & 1.0008 & 0.8535 & 0.4408 & 2.1859 & 1.0379 & 1.0864 & 1.1498 \\
\hline $2002-2003$ & 1.2167 & 0.9998 & 1.0292 & 1.0320 & 0.7133 & 1.3585 & 0.9540 & 1.2394 \\
\hline 2003-2004 & 1.3183 & 1.0052 & 0.8875 & 3.0935 & 0.3452 & 0.9365 & 1.0714 & 1.3793 \\
\hline 2004-2005 & 1.0625 & 1.0012 & 0.8489 & 1.0853 & 0.8977 & 1.0264 & 0.9665 & 1.2936 \\
\hline 2005-2006 & 1.18 & 1.0004 & 0.9674 & 0.5833 & 2.6011 & 0.6591 & 0.9060 & 1.3458 \\
\hline 2006-2007 & 1.1104 & 1.0027 & 0.9349 & 1.0664 & 0.7185 & 1.3051 & 0.8630 & 1.3726 \\
\hline 2007-2008 & 1.0167 & 0.9985 & 0.8613 & 0.5192 & 1.4488 & 1.3294 & 0.9478 & 1.2474 \\
\hline 2008-2009 & 1.0439 & 1.0002 & 0.9349 & 0.6913 & 1.1972 & 1.2082 & 0.9178 & 1.2163 \\
\hline 2009-2010 & 1.1111 & 0.9996 & 0.9068 & 1.0836 & 1.3084 & 0.7053 & 0.9321 & 1.3151 \\
\hline 2010-2011 & 1.0842 & 1.0035 & 0.9790 & 3.9408 & 0.2508 & 1.0120 & 0.9388 & 1.1756 \\
\hline 2011-2012 & 0.98 & 0.9994 & 0.9141 & 1.0703 & 1.1112 & 0.8408 & 0.9208 & 1.1650 \\
\hline 2012-2013 & 1.0685 & 1.0007 & 0.9892 & 2.4701 & 0.3709 & 1.0914 & 0.9205 & 1.1727 \\
\hline 2013-2014 & 1.0038 & 1.0025 & 0.9567 & 0.6304 & 1.5655 & 1.0133 & 0.8929 & 1.1723 \\
\hline 2014-2015 & 0.9989 & 0.9968 & 1.0184 & 0.3943 & 2.9906 & 0.8480 & 0.8983 & 1.0954 \\
\hline 2000-2005 & 1.8013 & 1.0092 & 0.6678 & 1.3061 & 0.4302 & 1.7797 & 1.0905 & 2.4511 \\
\hline 2005-2010 & 1.545 & 1.0014 & 0.6694 & 0.2426 & 4.2123 & 0.9787 & 0.6272 & 3.6749 \\
\hline 2010-2015 & 1.1383 & 1.0031 & 0.8603 & 2.6131 & 0.4756 & 0.8047 & 0.6404 & 2.0598 \\
\hline 1998-2015 & 3.3415 & 1.0015 & 0.3604 & 0.3002 & 2.3056 & 1.4447 & 0.5048 & 18.3411 \\
\hline
\end{tabular}


Table 8 Detailed additive decomposition results of the ERICE changes (unit: $10^{4}$ t)

\begin{tabular}{|c|c|c|c|c|c|c|c|c|}
\hline Stage & ${ }^{\Delta} \mathrm{C}_{\mathrm{TOT}}$ & $\Delta \mathrm{C}_{\mathrm{ES}}$ & $\Delta \mathrm{C}_{\mathrm{EI}}$ & ${ }^{\Delta} \mathrm{C}_{\mathrm{RE}}$ & $\Delta \mathrm{C}_{\mathrm{RI}}$ & ${ }^{\Delta} \mathrm{C}_{\mathrm{II}}$ & $\Delta \mathrm{C}_{\mathrm{IS}}$ & ${ }^{\Delta} \mathrm{C}_{\mathrm{O}}$ \\
\hline 1998-1999 & 172.28 & -64.56 & -160.26 & 200.07 & 938.48 & -1138.55 & 580.84 & -183.75 \\
\hline 1999-2000 & 116.81 & -12.59 & -225.84 & -5937.61 & 5237.41 & 700.20 & -83.23 & 438.47 \\
\hline $2000-2001$ & -51.83 & 11.45 & 32.31 & -830.39 & -556.44 & 1386.83 & 77.19 & -172.79 \\
\hline 2001-2002 & 369.10 & 4.77 & -902.92 & -4668.20 & 4456.09 & 212.11 & 471.95 & 795.30 \\
\hline 2002-2003 & 1274.98 & -1.06 & 187.06 & 204.57 & -2196.50 & 1991.94 & -306.35 & 1395.34 \\
\hline 2003-2004 & 2279.06 & 42.51 & -984.25 & 9313.12 & -8772.16 & -540.96 & 568.57 & 2652.22 \\
\hline 2004-2005 & 589.76 & 11.46 & -1594.41 & 796.80 & -1050.28 & 253.48 & -331.90 & 2504.62 \\
\hline 2005-2006 & 1804.78 & 4.12 & -361.14 & -5878.24 & $10,425.28$ & -4547.03 & -1077.12 & 3238.92 \\
\hline 2006-2007 & 1306.00 & 33.34 & -840.14 & 802.06 & -4123.77 & 3321.71 & -1838.06 & 3950.86 \\
\hline 2007-2008 & 220.01 & -19.25 & -1978.92 & -8683.63 & 4911.52 & 3772.11 & -710.81 & 2928.98 \\
\hline 2008-2009 & 586.18 & 2.99 & -918.92 & -5038.81 & 2457.35 & 2581.46 & -1170.99 & 2673.10 \\
\hline 2009-2010 & 1548.72 & -5.19 & -1439.04 & 1180.44 & 3953.23 & -5133.68 & -1034.83 & 4027.78 \\
\hline 2010-2011 & 1304.80 & 55.93 & -341.71 & $22,130.82$ & $-22,323.02$ & 192.20 & -1019.92 & 2610.50 \\
\hline 2011-2012 & -336.67 & -10.33 & -1493.79 & 1129.11 & 1753.84 & -2882.95 & -1372.92 & 2540.36 \\
\hline 2012-2013 & 1127.85 & 11.67 & -184.93 & $15,390.66$ & $-16,879.94$ & 1489.28 & -1410.60 & 2711.73 \\
\hline 2013-2014 & 67.12 & 44.43 & -781.00 & -8131.88 & 7898.67 & 233.21 & -1997.31 & 2801.00 \\
\hline 2014-2015 & -19.80 & -57.24 & 322.53 & $-16,423.33$ & $19,332.38$ & -2909.05 & -1893.15 & 1608.05 \\
\hline 2000-2005 & 4461.06 & 69.16 & -3060.59 & 2024.03 & -6393.81 & 4369.78 & 656.42 & 6796.07 \\
\hline 2005-2010 & 5465.69 & 17.30 & -5042.66 & $-17,796.64$ & $18,066.88$ & -270.24 & -5860.91 & $16,351.97$ \\
\hline 2010-2015 & 2143.31 & 51.14 & -2488.76 & $15,890.05$ & $-12,294.86$ & -3595.18 & -7372.90 & $11,953.83$ \\
\hline 1998-2015 & $12,359.15$ & 15.05 & $-10,455.79$ & $-12,326.24$ & 8557.61 & 3768.63 & -7002.70 & $29,802.59$ \\
\hline
\end{tabular}

Table 9 Cumulative decomposition results of the ERICE changes $(1998=1)$

\begin{tabular}{|c|c|c|c|c|c|c|c|c|}
\hline Year & $\Psi \mathrm{C}_{\mathrm{TOT}}$ & $\Psi \mathrm{C}_{\mathrm{ES}}$ & $\Psi \mathrm{C}_{\mathrm{EI}}$ & $\Psi \mathrm{C}_{\mathrm{RE}}$ & $\Psi \mathrm{C}_{\mathrm{RI}}$ & $\Psi \mathrm{C}_{\mathrm{II}}$ & $\Psi \mathrm{C}_{\mathrm{IS}}$ & $\Psi \mathrm{C}_{\mathrm{O}}$ \\
\hline 1999 & 1.0326 & 0.9880 & 0.9706 & 1.0380 & 1.1912 & 0.8088 & 1.1144 & 0.9663 \\
\hline 2000 & 1.055 & 0.9857 & 0.9316 & 0.3532 & 3.0823 & 0.9184 & 1.0977 & 1.0463 \\
\hline 2001 & 1.045 & 0.9878 & 0.9370 & 0.3041 & 2.7880 & 1.1796 & 1.1131 & 1.0142 \\
\hline 2002 & 1.115 & 0.9886 & 0.7997 & 0.1340 & 6.0943 & 1.2243 & 1.2092 & 1.1661 \\
\hline 2003 & 1.356 & 0.9884 & 0.8231 & 0.1383 & 4.3470 & 1.6632 & 1.1536 & 1.4453 \\
\hline 2004 & 1.788 & 0.9935 & 0.7305 & 0.4279 & 1.5006 & 1.5576 & 1.2360 & 1.9935 \\
\hline 2005 & 1.900 & 0.9947 & 0.6201 & 0.4644 & 1.3471 & 1.5987 & 1.1946 & 2.5788 \\
\hline 2006 & 2.242 & 0.9951 & 0.5999 & 0.2709 & 3.5039 & 1.0537 & 1.0823 & 3.4705 \\
\hline 2007 & 2.489 & 0.9978 & 0.5608 & 0.2889 & 2.5176 & 1.3752 & 0.9340 & 4.7636 \\
\hline 2008 & 2.531 & 0.9963 & 0.4830 & 0.1500 & 3.6474 & 1.8282 & 0.8852 & 5.9421 \\
\hline 2009 & 2.642 & 0.9965 & 0.4516 & 0.1037 & 4.3667 & 2.2088 & 0.8125 & 7.2274 \\
\hline 2010 & 2.936 & 0.9961 & 0.4095 & 0.1123 & 5.7134 & 1.5579 & 0.7573 & 9.5048 \\
\hline 2011 & 3.183 & 0.9996 & 0.4009 & 0.4427 & 1.4329 & 1.5766 & 0.7110 & 11.1738 \\
\hline 2012 & 3.119 & 0.9990 & 0.3665 & 0.4739 & 1.5923 & 1.3256 & 0.6547 & 13.0175 \\
\hline 2013 & 3.333 & 0.9997 & 0.3625 & 1.1705 & 0.5906 & 1.4467 & 0.6026 & 15.2656 \\
\hline 2014 & 3.345 & 1.0022 & 0.3468 & 0.7379 & 0.9245 & 1.4660 & 0.5381 & 17.8958 \\
\hline 2015 & 3.3417 & 0.9990 & 0.3532 & 0.2909 & 2.7649 & 1.2431 & 0.4833 & 19.6031 \\
\hline
\end{tabular}


Open Access This article is distributed under the terms of the Creative Commons Attribution 4.0 International License (http:// creativecommons.org/licenses/by/4.0/), which permits unrestricted use, distribution, and reproduction in any medium, provided you give appropriate credit to the original author(s) and the source, provide a link to the Creative Commons license, and indicate if changes were made.

\section{References}

Ang, B. W. (2004). Decomposition analysis for policymaking in energy: Which is the preferred method? Energy Policy, 32, 1131-1139.

Ang, B. W. (2005). The LMDI approach to decomposition analysis: A practical guide. Energy Policy, 33, 867-871.

Ang, J. B. (2009). $\mathrm{CO}_{2}$ emissions, research and technology transfer in China. Ecological Economics, 68, 2658-2665.

Ang, B. W., \& Liu, F. L. (2001). A new energy decomposition method: Perfect in decomposition and consistent in aggregation. Energy, 26, 537-548.

Ang, B. W., \& Liu, N. (2007). Handling zero values in the logarithmic mean Divisia index decomposition approach. Energy Policy, 35, 238-246.

Ang, B. W., Liu, F. L., \& Chew, E. P. (2003). Perfect decomposition techniques in energy and environmental analysis. Energy Policy, 31, 1561-1566.

Binswanger, M. (2001). Technological progress and sustainable development: What about the rebound effect? Ecological Economics, 36, 119-132.

Cansino, J. M., Roman, R., \& Ordonez, M. (2016). Main drivers of changes in $\mathrm{CO}_{2}$ emissions in the Spanish economy: A structural decomposition analysis. Energy Policy, 89, 150-159.

Cao, Y. J., Wang, X. F., Li, Y., Tan, Y., Xing, J. B., \& Fan, R. X. (2016). A comprehensive study on low-carbon impact of distributed generations on regional power grids: A case of Jiangxi provincial power grid in China. Renewable \& Sustainable Energy Reviews, 53, 766-778.

Cellura, M., Longo, S., \& Mistretta, M. (2012). Application of the structural decomposition analysis to assess the indirect energy consumption and air emission changes related to Italian households consumption. Renewable \& Sustainable Energy Reviews, 16, 1135-1145.

Chen, S. (2011). The abatement of carbon dioxide intensity in China: Factors decomposition and policy implications. The World Economy, 34, 1148-1167.

Collard, F., Feve, P., \& Portier, F. (2005). Electricity consumption and ICT in the French service sector. Energy Economics, 27, 541-550.

Deng, M., Li, W., \& Hu, Y. (2016). Decomposing industrial energy-related $\mathrm{CO}_{2}$ emissions in Yunnan province, China: Switching to low-carbon economic growth. Energies, 9, 23.

Guo, W., Sun, T., \& Dai, H. (2016). Effect of population structure change on carbon emission in China. Sustainability, 8, 225.

Hatzigeorgiou, E., Polatidis, H., \& Haralambopoulos, D. (2008). $\mathrm{CO}_{2}$ emissions in Greece for 1990-2002: A decomposition analysis and comparison of results using the arithmetic mean
Divisia index and logarithmic mean Divisia index techniques. Energy, 33, 492-499.

Hoekstra, R., \& van der Bergh, J. (2003). Comparing structural and index decomposition analysis. Energy Economics, 25, $39-64$.

IPCC. (2006). 2006 IPCC guidelines for national greenhouse gas inventories. Cambridge: Cambridge University Press.

IPCC. (2013). Summary for policy-makers. In Climate change 2013: the physical science basis. Cambridge: Contribution of working group I to the fifth assessment report of the intergovernmental panel on climate change/Cambridge University Press.

Jia, J. S., Kuang, C. H., \& Hu, L. L. (2014). Analysis on the energy consumption (EC) and carbon emission (CE) of tourism transport of Jiangxi province using the PLS method. In S. Feroz (Ed.), Energy engineering and environment engineering (Vol. 535, pp. 533-536).

Jung, S., An, K.-J., Dodbiba, G., \& Fujita, T. (2012). Regional energy-related carbon emission characteristics and potential mitigation in eco-industrial parks in South Korea: Logarithmic mean Divisia index analysis based on the Kaya identity. Energy, 46, 231-241.

Kerimray, A., Kolyagin, I., \& Suleimenov, B. (2018). Analysis of the energy intensity of Kazakhstan: From data compilation to decomposition analysis. Energy Efficiency, 11(2), 315-335.

Kopidou, D., Tsakanikas, A., \& Diakoulaki, D. (2016). Common trends and drivers of $\mathrm{CO}_{2}$ emissions and employment: A decomposition analysis in the industrial sector of selected European Union countries. Journal of Cleaner Production, 112, 4159-4172.

Lee, K., \& Oh, W. (2006). Analysis of $\mathrm{CO}_{2}$ emissions in APEC countries: A time-series and a cross-sectional decomposition using the log mean Divisia method. Energy Policy, 34, 2779 2787.

Lin, B., \& Xie, X. (2016). $\mathrm{CO}_{2}$ emissions of China's food industry: An input-output approach. Journal of Cleaner Production, 112, 1410-1421.

Lin, S. J., Lu, I. J., \& Lewis, C. (2006). Identifying key factors and strategies for reducing industrial $\mathrm{CO}_{2}$ emissions from a nonKyoto protocol member's (Taiwan) perspective. Energy Policy, 34, 1499-1507.

Liu, L.-C., Fan, Y., Wu, G., \& Wei, Y.-M. (2007). Using LMDI method to analyzed the change of China's industrial $\mathrm{CO}_{2}$ emissions from final fuel use: An empirical analysis. Energy Policy, 35, 5892-5900.

Liu, L., Wang, S. S., Wang, K., Zhang, R. Q., \& Tang, X. Y. (2016). LMDI decomposition analysis of industry carbon emissions in Henan province, China: Comparison between different 5-year plans. Natural Hazards, 80, 997-1014.

Lu, Z.; Yang, Y.; Wang, J. (2014). Factor decomposition of carbon productivity change in China's main industries: Based on the Laspeyres decomposition method. In International conference on applied energy, icae2014, Yan, J.; Lee, D.J.; Chou, S.K.; Desideri, U.; Li, H., Eds.; Vol. 61, pp 1893-1896.

Ma, C., \& Stern, D. I. (2008). China's changing energy intensity trend: A decomposition analysis. Energy Economics, 30, 1037-1053.

Marcucci, A., \& Fragkos, P. (2015). Drivers of regional decarbonization through 2100: A multi-model decomposition analysis. Energy Economics, 51, 111-124. 
Moutinho, V., Moreira, A. C., \& Silva, P. M. (2015). The driving forces of change in energy-related $\mathrm{CO}_{2}$ emissions in eastern, western, northern and southern Europe: The LMDI approach to decomposition analysis. Renewable \& Sustainable Energy Reviews, 50, 1485-1499.

Moutinho, V., Madaleno, M., \& Silva, P. M. (2016). Which factors drive $\mathrm{CO}_{2}$ emissions in EU-15? Decomposition and innovative accounting. Energy Efficiency, 9(5), 1087-1113.

Nie, H., Kemp, R., Vivanco, D. F., \& Vasseur, V. (2016). Structural decomposition analysis of energy-related $\mathrm{CO}_{2}$ emissions in China from 1997 to 2010. Energy Efficiency, 9(6), 13511367.

Qu, J. S., Qin, S. S., Liu, L., Zeng, J. J., \& Bian, Y. (2016). A hybrid study of multiple contributors to per-capita household $\mathrm{CO}_{2}$ emissions (HCEs) in China. Environmental Science and Pollution Research, 23(7), 6430-6442.

Ren, S., Fu, X., \& Chen, X. (2012). Regional variation of energyrelated industrial $\mathrm{CO}_{2}$ emissions mitigation in China. China Economic Review, 23, 1134-1145.

Shao, S., Yang, L., Yu, M., \& Yu, M. (2011). Estimation, characteristics, and determinants of energy-related industrial $\mathrm{CO}_{2}$ emissions in Shanghai (China), 1994-2009. Energy Policy, 39, 6476-6494.

Shao, S., Huang, T., \& Yang, L. (2014). Using latent variable approach to estimate China's economy-wide energy rebound effect over 1954-2010. Energy Policy, 72, 235-248.

Shao, S., Yang, L. L., Gan, C. H., Cao, J. H., Geng, Y., \& Guan, D. B. (2016). Using an extended LMDI model to explore techno-economic drivers of energy-related industrial $\mathrm{CO}_{2}$ emission changes: A case study for Shanghai (China). Renewable \& Sustainable Energy Reviews, 55, 516-536.

Sorrell, S., \& Dimitropoulos, J. (2008). The rebound effect: Microeconomic definitions, limitations and extensions. Ecological Economics, 65, 636-649.

Sorrell, S., Dimitropoulos, J., \& Sommerville, M. (2009). Empirical estimates of the direct rebound effect: A review. Energy Policy, 37, 1356-1371.

Specht, E., Redemann, T., \& Lorenz, N. (2016). Simplified mathematical model for calculating global warming through anthropogenic $\mathrm{CO}_{2}$. International Journal of Thermal Sciences, 102, 1-8.

State Council of the People's Republic of China (SCPRC). (2011). The 12th Five-Year Plan outline of national economy and social development of People's Republic of China. http://news.xinhuanet.com/politics/2011-03/16 /c_121193916.htm. Accessed 20 March 2018.

Tan, Z., Li, L., Wang, J., \& Wang, J. (2011). Examining the driving forces for improving China's $\mathrm{CO}_{2}$ emission intensity using the decomposing method. Applied Energy, 88, 4496-4504.

Tian, Y., Zhu, Q., \& Geng, Y. (2013). An analysis of energyrelated greenhouse gas emissions in the Chinese iron and steel industry. Energy Policy, 56, 352-361.

Wang, C., Chen, J. N., \& Zou, J. (2005). Decomposition of energy-related $\mathrm{CO}_{2}$ emission in China: 1957-2000. Energy, $30,73-83$.
Wang, W., Kuang, Y., \& Huang, N. (2011). Study on the decomposition of factors affecting energy-related carbon emissions in Guangdong province, China. Energies, 4, 2249-2272.

Wang, W., Liu, R., Zhang, M., \& Li, H. (2013). Decomposing the decoupling of energy-related $\mathrm{CO}_{2}$ emissions and economic growth in Jiangsu province. Energy for Sustainable Development, 17, 62-71.

Wood, R., \& Lenzen, M. (2006). Zero-value problems of the logarithmic mean Divisia index decomposition method. Energy Policy, 34, 1326-1331.

Xiao, H., Wei, Q. P., \& Wang, H. L. (2014). Marginal abatement cost and carbon reduction potential outlook of key energy efficiency technologies in china's building sector to 2030 . Energy Policy, 69, 92-105.

Xiao, B., Niu, D., \& Guo, X. (2016). The driving forces of changes in $\mathrm{CO}_{2}$ emissions in China: A structural decomposition analysis. Energies, 9, 259.

Xiong, C., Yang, D., \& Huo, J. (2016). Spatial-temporal characteristics and LMDI-based impact factor decomposition of agricultural carbon emissions in Hotan prefecture, China. Sustainability, 8, 262.

Xu, S. C., Zhang, W. W., He, Z. X., Han, H. M., Long, R. Y., \& Chen, H. (2017). Decomposition analysis of the decoupling indicator of carbon emissions due to fossil energy consumption from economic growth in China. Energy Efficiency, 10(6), 1365-1380.

Yang, Z., Liu, H., Xu, X., \& Yang, T. (2016). Applying the water footprint and dynamic structural decomposition analysis on the growing water use in China lduring 1997-2007. Ecological Indicators, 60, 634-643.

Zhang, G. X., \& Liu, M. X. (2014). The changes of carbon emission in china's industrial sectors from 2002 to 2010: A structural decomposition analysis and input-output subsystem. Discrete Dynamics in Nature and Society, 798576, 1-9. https://doi.org/10.1155/2014/798576.

Zhang, Q. G., Shen, W. Q., Wei, L. A., \& Chen, S. H. (2012). Development strategies of low-carbon economy in Jiangxi province. In J. Wu, J. Yang, N. Nakagoshi, X. Lu, \& H. Xu (Eds.), Natural resources and sustainable development ii, pts 1-4 (Vol. 524-527, pp. 2510-2516).

Zhang, M., Liu, X., Wang, W., \& Zhou, M. (2013). Decomposition analysis of $\mathrm{CO}_{2}$ emissions from electricity generation in China. Energy Policy, 52, 159-165.

Zhao, M., Tan, L., Zhang, W., Ji, M., Liu, Y., \& Yu, L. (2010). Decomposing the influencing factors of industrial carbon emissions in Shanghai using the LMDI method. Energy, 35, 2505-2510.

Publisher's note Springer Nature remains neutral with regard to jurisdictional claims in published maps and institutional affiliations. 